\title{
Understanding the Spatial Trajectories of Minority Groups: An Approach that Examines their Demographic, Cultural and Socio- economic Characteristics
}

\author{
Philip Sapiro
}

\begin{abstract}
Population researchers have contributed to the debate on minority group distribution and disadvantage and social cohesion by providing objective analysis. A plethora of new distribution measurement techniques have been presented in recent years, but they have not provided sufficient explanatory power of underlying trajectories to inform ongoing political debate. Indeed, a focus on trying to summarise complex situations with readily understood measures may be misplaced. This paper takes an alternative approach and asks whether a more detailed analysis of individual and environmental characteristics is necessary if researchers are to continue to provide worthwhile input to policy development. Using England and Wales as a test bed, it looks at four small sub-populations (circa 250,000 at the turn of the century) - two based on ethnic grouping: Bangladeshi and Chinese; and two based on an under-researched area of cultural background, religion: Jews and Sikhs. Despite major differences in longevity of presence in the UK, age profile, socio-economic progress, and levels of inter-marriage, there are, at a national level, parallels in the distribution patterns and trajectories for three of the groups. However, heterogeneity between and within the groups mean that at a local level, these similarities are confounded. The paper concludes that complex interactions between natural change and migration, and between suburbanisation and a desire for group congregation, mean that explanations for the trajectory of distribution require examination of data at a detailed level, beyond the scope of index-based methods. Such analyses are necessary if researchers are to effectively contribute to future policy development.
\end{abstract}

Keywords: Spatial distribution • Index of dissimilarity · Ethnic group • Religion • Migration · Natural change 


\section{Introduction}

Population geographers and other social scientists have been investigating and analysing the spatial distribution of minority groups, and the impact of group segregation on the stability of society for many decades. This work has made a positive contribution to academic and political debate in many parts of the world, by providing an objective analysis of the extensive amounts of data that are available (for example, Rugh/Massey 2010; Âs/und/Skans 2010; Shon 2010; Jivraj/Simpson 2015; Catney 2016). Frequently, this has taken the form of assessing and quantifying the pattern of distribution and its change over time through the use of a wide variety of indices of distribution.

The utility in attempting to summarise a complex picture in a readily understood measure that can be transferred from one situation to another clearly has benefits. However, given the need to explain, understand, and predict changes in spatial distribution if policy advice is to be developed, a focus on measurement techniques may be misplaced. It may have contributed to an undue prominence being given to residential segregation, and attempts to reduce it per se, rather than considering positive aspects of group congregation, or identifying location-specific underlying health, qualifications, employment or other socio-economic disadvantages. Indeed, "housing policies have a limited effect on ethnic concentration, not only because they often contradict each other, but also because they fail to address the main causes of segregation" (Bolt 2009: 397; see also van Ham/Manley 2009; Dhalmann/ Vilkama 2009; Münch 2009; Kempen/Bolt 2009; and Holmqvist/Bergsten 2009).

This paper proposes taking an alternative approach. It suggests that a more detailed analysis of individual and environmental characteristics is necessary if researchers are to continue to provide worthwhile input into the discussion of segregation/integration, disadvantage, and social cohesion. As a case study, analysis is presented for four small cultural groups, based on output from the England and Wales 2001 and 2011 censuses.

\section{Recent Measurement Techniques}

Numerous indices have been used to measure various aspects of spatial distribution, with in-depth reviews carried out to reach a consensus on their use (Duncan/ Duncan 1955; Massey/Denton 1988; Simpson 2007). Despite a long period in which use of the Index of Dissimilarity $(D)$ predominated, in recent times a wide range of alternative approaches have been developed. However, few of these have been widely adopted; indeed, as discussed below, a number of researchers have revisited their approaches in subsequent studies.

Despite its popularity and its easy interpretation as "the proportion of a group that would have to move to be distributed through localities like the rest of the population" (Simpson 2007: 421), three types of weakness in $D$ have long been recognised: 
- mathematical/theoretical weaknesses (Cortese et al. 1976; Taeuber/Taeuber 1976; Winship 1977; Voas/Williamson 2000)

- Variability of results depending on geographic units - the results of index calculations suffer from the modifiable areal unit problem (MAUP) (Openshaw 1984) and zonation issues (Rees et al. 2017).

- The fundamental aspatiality of the measure (Wong 2016) - in that the absolute and relative positions of the spatial units/zones being used have no impact on the resultant value of the index. The checkerboard analogy, presented by White (1983), demonstrates this in a very clear manner.

Examination of a number of papers that have been published since the release of small scale outputs from the 2011 England and Wales census shows that a wide range of alternative approaches have been applied. These attempt to meaningfully summarise levels of integration or segregation of minority groups, and overcome the weaknesses.

Harris and Owen (2018) attempted to enhance $D$ by developing a Spatial Multilevel Index of Dissimilarity. They considered the impact of adjoining areas at different scales, having previously proposed an Index of Discontinuity (based on differences in values of $D$ in adjoining zones) (Harris 2014). Another approach sought to apply $D$ to measure unevenness in combination with Moran's / spatial autocorrelation coefficient to measure clustering (Catney 2017). However, in a later paper, Catney (2018) used both $D$ and the Index of Isolation $(P)$ to examine spatial variation.

An alternative methodology was developed by Johnston (Johnston et al. 2015, 2016). They employed a rule-based approach that categorised areas according to the percentage share of the population provided by white, all non-white, and individual non-white ethnic groups. In parallel with this Jones et al. (2015) were developing yet a further technique that used a modified log-Poisson model based on the degree of over- or under-representation of each group compared with its average presence. This was subsequently enhanced by the introduction of a multi-scale element (Johnston et al. 2016).

Of course, these matters are not solely an England and Wales issue. Internationally, there is a considerable body of research that makes use of assessment of the presence in the nearest $k$-neighbours of members of the same or different ethnic/ racial/nationality group (Johnston et al. 2004; Reardon et al. 2008). The base unit can be an individual, a small census tract, or gridded data. The technique allows the value of $k$ to be varied to examine group concentrations at a variety of scales, addressing the MAUP issue. In recent years, variations of, and enhancements to, the technique have been applied in Los Angeles and Sweden (Östh et al. 2015; Clark et al. 2015), Seattle (Fowler 2016), and Amsterdam, Utrecht, and Groningen (Netherlands) (Petrović et al. 2018). Geographically wider studies include those of several US cities in the context of the USA as a whole (Hennerdal/Nielsen 2017), and a comparative study of Belgium, Denmark, Netherlands, and Sweden (Andersson et al. 2018).

Overall, we can say that a wide range of alternative approaches and enhancements to earlier indices have been tested. In the case of the UK, their lack of adoption by other researchers, and the apparent continuing need for the original authors 
to revise their techniques, suggests that attempting to measure and summarise spatial distribution is not advancing the understanding of distribution or the forecasting of its future trajectory. The thesis of the current paper, therefore, is that in this context such approaches should be set to one side.

\section{Approach of this paper}

A closer examination of the variation in the characteristics of minority groups may improve the explanation of change in spatial distribution and its underlying drivers. It is important that this is better understood since cultural and "ethnic diversity, which is now a key characteristic of contemporary society ... is an issue of public, policy, political, and academic interest." (Catney 2016: 13).

Using England and Wales as a test bed, this paper seeks to broaden the discussion on understanding spatial distribution trends. It takes the view that heterogeneity within groups means that a more detailed exploration of the data is required if a clearer understanding of spatial distribution trajectory is to be achieved. The 2001 census identified four explicitly defined groups (that is, excluding "mixed" and "other" groupings) with a population of around a quarter of a million people - Bangladeshis, Chinese, Jews, and Sikhs. All four groups are examined side by side, using data from the 2001 and 2011 censuses, with the majority white British group used as a benchmark where appropriate.

The case for the selection of these four groups (in addition to their similarity in size) is that:

- Religion is an under-researched area of cultural identity, compared with ethnic background; presenting detailed analysis of spatial distribution change for Jews and Sikhs for the first time seeks to redress this.

- This size of group may display a different dynamic to the larger ethnic groups that other researchers have examined.

- As described later, despite similarity in size, the groups demonstrate different demographic and socio-economic characteristics, with a notable variation in their length of material presence in Britain, the importance of students, and levels of recent immigration.

The focus is thus on two groups based on religion, and two based on ethnic background. Similarities and differences in their trajectories provide an interesting and varied basis for the investigation of spatial distribution.

This paper examines census data at a detailed geographic level. For a higher level comparison of ethnic groups in recent UK censuses see Jivraj/Simpson 2015; Finney/Simpson 2008; Simpson/Finney 2009, and for the 1991 census see Rees et al. 1995. British studies need to be seen in the context of interest in cultural group spatial distribution across the globe. Recent international studies, making use of census data, include: an analysis of characteristics of foreign nationals in the Czech Republic (Prídalová/Hasman 2018); an examination of religious diversity in Australia (Bouma/Hughes 2014); a wide-ranging and detailed examination of ethnic diversity 
in Indonesia (Ananta et al. 2015); and a multi-national investigation of ethnic, religious and linguistic diversity in Africa (Gershman/Rivera 2018).

UK censuses are accepted as being of high quality, and undergo a strong validation process (ONS 2009). However, it is worth briefly considering some aspects of the ethnic group and religion questions and responses on which this paper focuses, and the differences between them. Pre-defined response categories were specified for both questions, an approach that can sometimes be regarded as influencing the replies given, as can the order of questions (Blaikie 2000; Voas/Bruce 2004). Uniquely, the religion question was voluntary, and ONS accepted blank responses (about 7 percent of the total) - allocating them to a "religion not stated" category. As with all other questions, the ethnic group question was compulsory though 3 percent of respondents did not answer it; in these cases ONS imputed an answer (ONS 2012). Another difference between the ethnic group and religion questions was that ONS provided "advice" as to what the ethnic group question was seeking to elucidate: "tick one box to best describe your ethnic group or background". However, the religion question simply asked "What is your religion?" (ONS 2011), leaving it to the respondent to determine whether this might mean, for example, belief, family affiliation, or membership. There was a specific concern that the Jewish response rate might be low because of concerns about biblical prohibition on counting Jews (see Hosea, 2:1), or holocaust-related mis-use of census data (Brasz 2001). Indeed evidence of some undercount amongst strictly orthodox Jews was found, certainly as regards the 2001 census (Graham/Waterman 2005; Voas 2007).

Ultimately, however, the focus of this paper is on changes over time and underlying characteristics of the members of the groups, and not numerical comparisons between the groups or absolute measures of segregation/congregation. On this basis, use of the census outputs without additional manipulation is a suitable basis on which to proceed.

\section{Theoretical background}

Questions about the spatial distribution of minority populations and how this might change over time are not new. As long ago as 1926, Park recognised that change in residential location was associated with levels of education, employment and income (Park 1926). Subsequently, Gordon (1964) defined various social/cultural levels of assimilation that he believed represented a trajectory along which minority groups might travel. Twenty years later Massey (1985: 316) set out to develop "a modern theory of ethnic residential segregation", under which immigrant groups would initially form concentrations, but would gradually disperse into the wider community as their socio-economic circumstances improved. This approach was later criticised, for example by Nagel (2009) and Wright et al. (2005), and alternative theories/approaches developed (see for example: Portes/Zhou 1993; Iceland/Nelson 2008; Ehrkamp 2005). Attention has also been given to the positive aspects of group concentration or congregation (Peach 1996; Phillips et al. 2007; Dunn 1998). 
Whilst internal (and international) migration is important in bringing about change in spatial distribution of groups (Rees et al. 2013), it is not the only mechanism in play. Other processes, such as natural change due to births and deaths, can have a larger impact on segregation and neighbourhood mix (Bailey 2012).

In summary, several factors have confounded the simplicity of traditional theories about spatial distribution: heterogeneity amongst groups; uncertain economic conditions; changing outlook of later generations; and changing political and social circumstances that impact on individuals' aspirations and expectations. However, most researchers continue to find some form of link between socio-economic advancement, cultural preferences and assimilation, and changes in spatial distribution.

\section{Overview of the Four Cultural Groups}

Prior to examining the spatial distribution of the four cultural groups at a detailed level (and how this changes over time), this section provides an overview of the characteristics of each group. These characteristics, all linked to theories of spatial distribution, may provide us with expectations about the likely distribution and trajectory of distribution of the groups.

In this section, four aspects are considered:

- Longevity of material presence in, and scale of recent immigration to, Britain - which may influence the level of continuing presence in immigrant settlement areas;

- Age profile and thus whether groups might be increasing in presence due to an excess of births over deaths;

- Socio-economic status - where improvement might be associated with advancement up the property ladder, and relocation to more sought-after areas;

- Inter-marriage - as a marker for cultural assimilation - which some commentators have associated with the post-physical integration period.

\section{Longevity of material presence and recent immigration levels}

Using census data in parallel with existing research - Rees/Butt 2004; Schmool/Cohen 1998; Peach/Gale 2003; Eade et al. 1996 - it is possible to gain an appreciation of the scale and rate of growth for these groups over a longer period. Census data are available for the ethnic groups from 1991 onwards and for religions from 2001. The main sources used by these authors to produce estimates for earlier years were: census country of birth data (Chinese and Bangladeshis); relationships between number of registered places of worship and numbers of worshipers (Sikhs); and a comprehensive database of burials with ages at death (Jews). Figure 1 identifies the trajectory of population change for each group over the last 80 years; for 
Fig. 1: Group population profiles 1931-2011 (England and Wales)

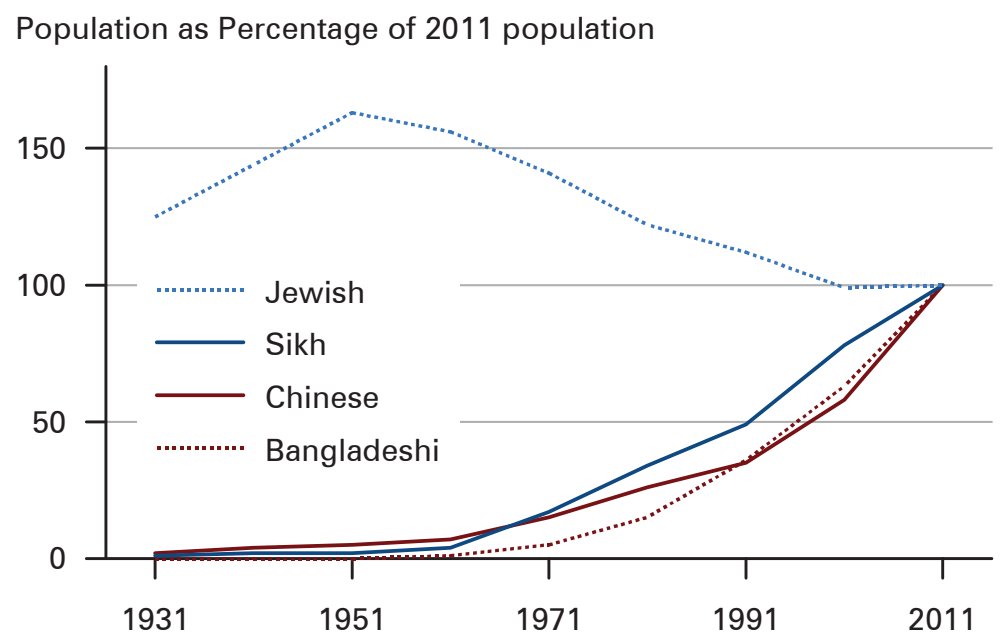

Source: see text for commentary on sources and derivation of data for this graph

each group, 100 percent equals the 2011 census population. ${ }^{1}$ Inevitably there must be a margin of error around the figures, but the purpose in including the diagram is only to establish the general shape of the profiles and the extent to which the four groups are similar to or differ from each other.

The profile for the Jewish population is clearly in stark contrast to the other groups. Over the last 60 years, the Jewish group's population has gradually fallen from its peak, which was more than 50 percent higher than the current population. The other groups have all grown from no more than 5 percent of their 2011 figures. This confirms that Jews have been present in the UK in significant numbers for a much longer period than the other groups considered here.

The graph can be supplemented by examining information on year of arrival in the UK of those present at the 2011 census by making use of the 2011 Census Microdata Individual Safeguarded Sample files (ONS 2014) - a 10 percent anonymised sample of the England and Wales 2011 census returns - see Table 1.

The profile for the Chinese group differs from the others, with just under half having arrived since 2001, and with students making up almost half of that element. The majority of students are likely to be transient visitors to the UK, located in key university towns. The overall impact on spatial distribution of such a material proportion of the group having arrived since 2001 depends on whether they have settled in areas where the Chinese group is already present (Luk 2008, 2009; Lymperopoulou 2013).

1 The 2011 population of each group, according to the census was: Bangladeshi: 447,201; Chinese: 393,141; Jewish 265,073; and Sikh: 423,345. (Source: census table DC2201EW as corrected by ONS on 26 February 2015). 
Tab. 1: 2011 England \& Wales usual residents - year of arrival

\begin{tabular}{|c|c|c|c|c|c|c|c|c|c|}
\hline \multirow[t]{4}{*}{ Group } & \multirow[t]{3}{*}{ UK born } & \multicolumn{6}{|c|}{ Year of arrival in UK } & \multirow[t]{4}{*}{ Total } & \multirow{4}{*}{$\begin{array}{c}\text { Sample } \\
\text { size }\end{array}$} \\
\hline & & before & 1971- & 1991- & 2001- & 200 & 7-11 & & \\
\hline & & 1971 & 1990 & 2000 & 2006 & $\begin{array}{c}\text { non- } \\
\text { student }\end{array}$ & student & & \\
\hline & \multicolumn{7}{|c|}{ in \% } & & \\
\hline Bangladeshi & 52 & 3 & 19 & 10 & 9 & 5 & 2 & 100 & 44865 \\
\hline Chinese & 24 & 5 & 15 & 11 & 16 & 9 & 20 & 100 & 39099 \\
\hline Jewish & 81 & 4 & 4 & 3 & 3 & 3 & 1 & 100 & 26394 \\
\hline Sikh & 57 & 15 & 12 & 5 & 6 & 4 & 1 & 100 & 41962 \\
\hline
\end{tabular}

Source: Author analysis from the 2011 Census Microdata Individual Safeguarded Regional and LA files

Traditional theory would lead us to expect that Jews would be highly dispersed amongst the wider British population, but we already know that this is not the case (Simpson 2012). However, we might expect to find that their physical location is away from the settlement areas occupied a century ago.

\section{Age Profile}

Table 2 summarises a number of characteristics taken from 2011 census outputs, including information on age profile. The proportion of the Bangladeshi community aged below 15, at 46 percent, is twice that of any other group listed here and indicates that the population is expanding at a fast rate through natural change (see also Simpson/Jivraj 2015). The Jewish group has a larger proportion of its population in the aged 65 and over band than all of the other groups, and has the potential for shrinkage through natural change. The absence of a significant elderly presence in the Sikh and Chinese communities will result in an excess of births over deaths. We should expect to see these natural changes reflected in changing spatial density.

\section{Socio-economic status}

We can anticipate that higher incomes will be a pre-requisite for enabling households to live in (or to move to) the more sought-after/affluent home-owning areas. Indeed, the median weekly wage (for the 2006-2008 period) for male employees living in a home with a mortgage was 37 percent higher than for those in private rented accommodation and 65 percent higher than those living in social housing (Hills et al. 2010). Unfortunately, the census does not collect information on incomes, but it presents information on areas of employment and the roles played in those occupations - socio-economic status (see Table 2). Moreover, Hills et al. (2010) demonstrate that National Statistics Socio-economic class (NS-Sec) is a useful proxy for income - with a gradual diminution in median male full-time employee hourly wages from NS-Sec Class 1 (higher managerial, administrative and professional occupations) to Class 7 (routine occupations). For those adults who have 


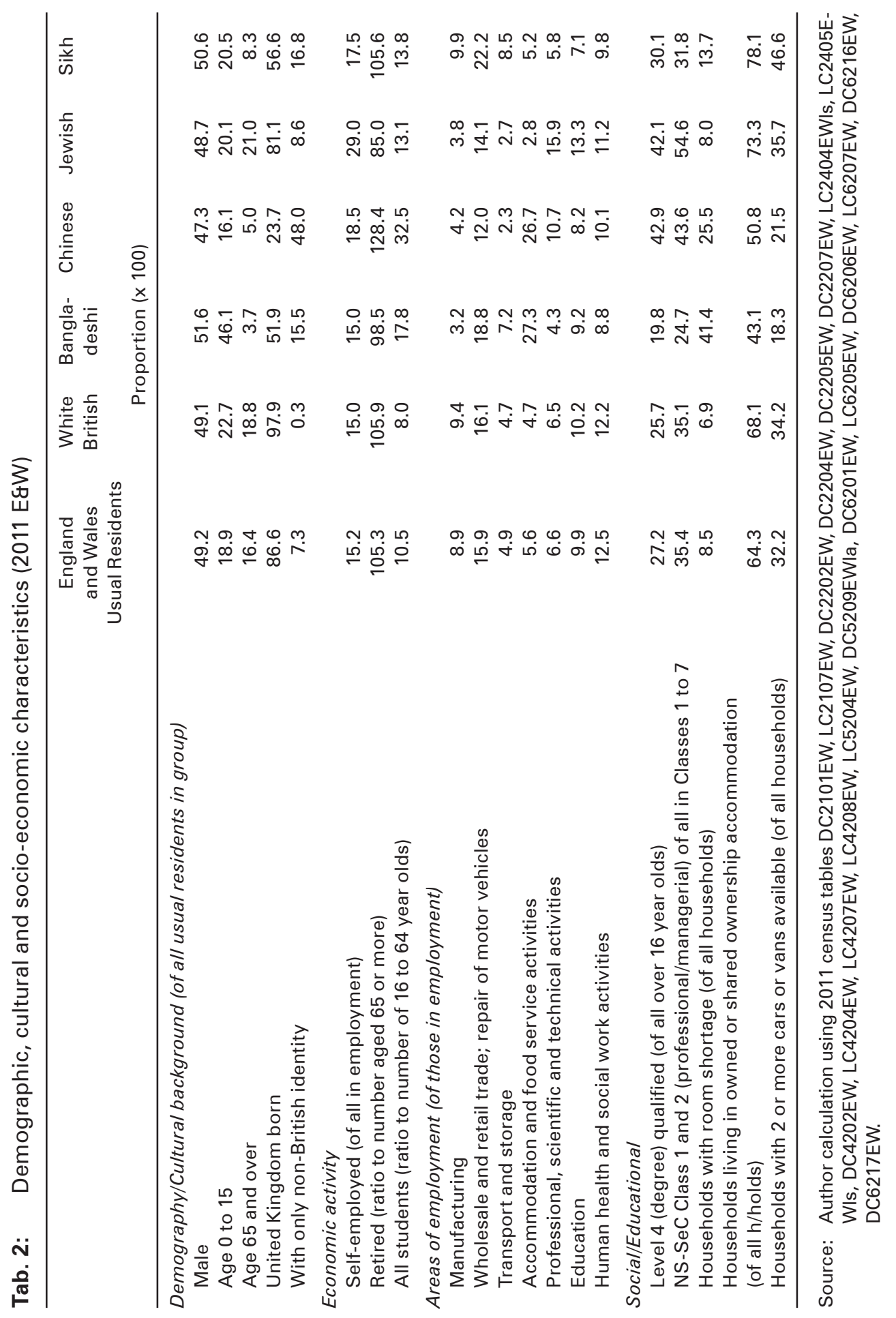


ever worked (and excluding current full time students), Table 2 demonstrates that a higher proportion of Chinese and Jews accommodate managerial and professional positions (NS-SeC 1 and 2) than do the white British, with Bangladeshis and Sikhs including lower proportions. However, for England and Wales residents (aged 16 or over) overall, 14 percent have either never worked or are full time students. For the Chinese group the proportion is 40 percent (census table LC6206EW). Once these individuals are included, the proportion of Chinese adults falling into the NS-Sec Class 1 and 2 categories falls below the England and Wales average.

Despite a relatively low proportion of managerial and professional positions in the Sikh group, that group exhibits the highest levels of home and two-car ownership of all groups. This apparent disconnect between NS-Sec and home-ownership (and its likely consequential impact on spatial distribution) is investigated here. It appears that certain factors relating specifically to the Sikh community, not directly discernible from the census outputs, are in play. The British Sikh community has produced an annual report about the community since 2013. The 2014 report analysed responses to a questionnaire that included relevant questions on demography, income, and property. Caution is necessary in making use of information in detail from the report as the analysis was based on a non-validated survey sample, largely self-selected via social media or word of mouth (BSR Team 2014). However, the report indicates that two-thirds of the sample live in households with four or more people and almost half of the adult respondents are living with one or more parent. Two thirds have household incomes above the average for all UK households. There is clearly a tradition of property ownership in the Sikh community; the BSR 2014 indicating that half of all families own more than one property in the UK, and half also own property in India. In addition a third of families own a business in the UK (BSR Team 2014). So it seems likely that the high home ownership level among the Sikh group arises through three factors: a higher total income per household due to a greater number of employed persons per residence (arising from household size and multi-generational households); income through business ownership, noting that the relationship of wages to NS-Sec only relates to employees; and the potential for non-employment related income through property ownership elsewhere in the UK and overseas.

Overall, therefore, we might expect larger proportions of the Jewish and Sikh groups to be located in more sought after residential areas, where home-ownership predominates, compared with the other cultural groups.

The index of multiple deprivation (IMD) provides an alternative way of considering the economic/financial link with location of residence. The Department of Communities and Local Government measures each LSOA ${ }^{2}$ in terms of its level of deprivation. The index incorporates a range of measures associated with income, employment, health and disability, education skills and training, barriers to hous-

2 The Office for National Statistics (ONS) defined output areas (OAs) as the key geographic building block for census output. OAs (average population 300) have a consistency of housing type and tenure and are grouped into LSOAs (typical population 1600); LSOAs are grouped into MSOAs (population around 7800). 
ing and other services, crime and living environment (DCLG 2011). The LSOAs are ranked using the deprivation score, and it is customary to categorise them based on the decile into which they fall (decile 1, most deprived, to decile 10, least deprived). To provide a fixed base to monitor change in spatial distribution, the 2010 index (based on data collected between the 2001 and 2011 censuses) has been used here. The link between NS-Sec and wage income already described has been found to apply also to the deciles of the IMD (Hills et al. 2010).

Figure 2 indicates the proportion of the 2001 population of each of the small cultural groups that were resident in LSOAs falling into each decile of the index. It is important to note that the index relates to the mean status of the totality of residents of the LSOA - not just members of the groups under examination.

Fig. 2: Allocation of 2001 group population to IMD deciles

Proportion of 2001 Group Population falling into decile in percent

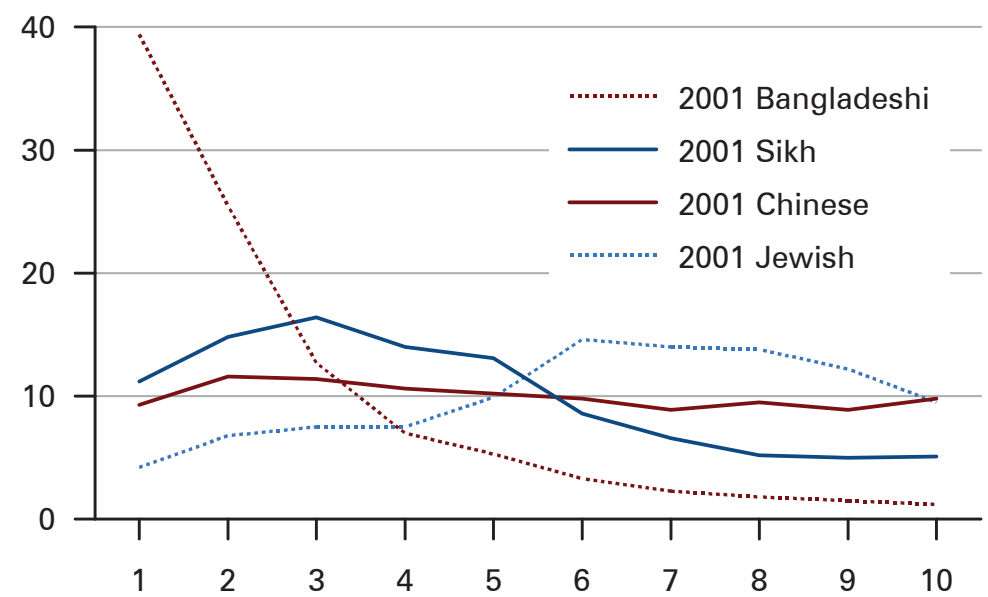

Decile of Multiple Deprivation: most (1) to least (10) deprived

Source: Author calculated based on combining 2001 census output with 2010 IMD data

The graph shows that, in 2001, the Bangladeshi population was most concentrated in the most deprived deciles (particularly decile 1), with below average proportions in deciles 4 to 10 . The Sikh group is over-represented in deciles 1 to 5 , and under-represented in deciles 6-10 though to a much lesser degree. The Chinese group is evenly spread, with the Jewish group demonstrating a mirror-image of the Sikh pattern.

The trajectory of change in group distribution is a key issue under investigation in this paper. Therefore, rather than simply including an equivalent graph based on the 2011 population, Figure 3 homes in on the changes over the 2001 to 2011 period. It shows the percentage point change in split between deciles that has occurred to 
Fig. 3: Percentage point change in IMD decile 2001-2011

2001 to 2011 Change in Proportion of Group Population in decile in percent

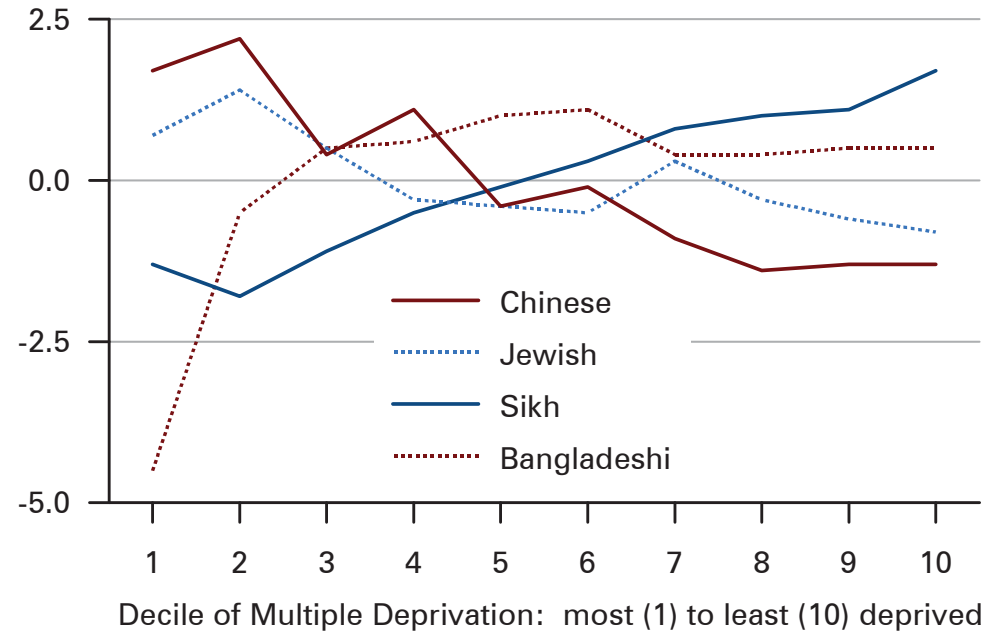

Source: Author derived based on 2001 and 2011 census output and 2010 IMD data

the population of each group in the intercensal period, to allow a link between social advancement and spatial distribution change to be investigated.

Both the Bangladeshi and Sikh groups have seen a reduction in the proportion of their populations resident in the most deprived deciles. This represents a pattern of continuing socio-economic advancement, though the shape of the curve and pivot points of zero change are differently located. Conversely, the Chinese and Jewish lines show the opposite trend. The Chinese trend (which is almost a mirror-image of the Sikh line) is probably explained through the very large increase in student numbers over the decade, given that in most major cities, student residences tend to be found in less-affluent areas. The Jewish line is less easily explained. It may suggest that the Jewish group's socio-economic progress over the last century has now plateaued and is in a period of fluctuation; or it may simply reflect the marked difference in age profiles and fertility levels in different parts of the community (Staetsky/Boyd 2015).

The question is whether the level of change demonstrated here is sufficient to be reflected in a noticeable pattern of geographic change on the ground. For example, Figure 3 shows that in 2011 a smaller proportion of the Bangladeshi population is found in LSOAs in decile 1, and a greater proportion is found in decile 3 . If the affected LSOAs are close to each other the actual geographic/spatial impact of the IMD decile change would be less noticeable than if the LSOAs concerned happen to be more remote from each other. 


\section{Inter-marriage}

Table 3 summarises the census information available on the cultural identity of spouses $^{3}$ and other partners of partnered members of the groups under examination. Note that for the groups based on religion, relationships where the partner did not respond to the question on religion are excluded; an equivalent consideration for ethnic group does not apply as ONS imputes an ethnic group for non-respondents.

Tab. 3: $\quad$ Proportion of partnered group members with non-group partners

\begin{tabular}{lrrrrrrrr}
\hline & \multicolumn{3}{c}{$\begin{array}{c}\text { Married } \\
\text { non-group } \\
\text { partner }\end{array}$} & total & $\begin{array}{c}\text { Cohabiting } \\
\text { total }\end{array}$ & $\begin{array}{c}\text { All partnerships } \\
\text { non-group } \\
\text { partner }\end{array}$ & \multicolumn{2}{c}{$\begin{array}{c}\text { total } \\
\text { non-group } \\
\text { partner }\end{array}$} \\
\hline Bangladeshi & & & & & & & & \\
$\quad$ Men & 74,974 & 4,652 & $6 \%$ & 4,243 & 1,781 & 79,217 & 6,433 & $8 \%$ \\
$\quad$ Women & 74,380 & 4,062 & $5 \%$ & 3,454 & 1,206 & 77,834 & 5,268 & $7 \%$ \\
$\quad$ Total & 149,354 & 8,714 & $6 \%$ & 7,697 & 2,987 & 157,051 & 11,701 & $7 \%$ \\
Chinese & & & & & & & & \\
$\quad$ Men & 51,936 & 8,365 & $16 \%$ & 11,203 & 4,471 & 63,139 & 12,836 & $20 \%$ \\
$\quad$ Women & 68,046 & 24,479 & $36 \%$ & 14,587 & 8,133 & 82,633 & 32,612 & $39 \%$ \\
$\quad$ Total & 119,982 & 32,844 & $27 \%$ & 25,790 & 12,604 & 145,772 & 45,448 & $31 \%$ \\
Jewish & & & & & & & & \\
$\quad$ Men & 54,125 & 12,364 & $23 \%$ & 6,190 & 4,202 & 60,315 & 16,566 & $27 \%$ \\
$\quad$ Women & 53,609 & 11,876 & $22 \%$ & 6,029 & 4,109 & 59,638 & 15,985 & $27 \%$ \\
$\quad$ Total & 107,734 & 24,240 & $22 \%$ & 12,219 & 8,311 & 119,953 & 32,551 & $27 \%$ \\
Sikh (2001 data) & & & & & & & & \\
$\quad$ Men & 71,170 & 3,658 & $5 \%$ & 2,682 & 1,481 & 73,852 & 5,139 & $7 \%$ \\
$\quad$ Women & 70,437 & 2,925 & $4 \%$ & 2,274 & 1,073 & 72,711 & 3,998 & $5 \%$ \\
$\quad$ Total & 141,607 & 6,583 & $5 \%$ & 4,956 & 2,554 & 146,563 & 9,137 & $6 \%$ \\
\hline
\end{tabular}

Source: 2001 tables C0400, C0629; 2011 tables CT0458,СT0459, СT0460, CT0461, and 2011 un-numbered tables from "What does the 2011 Census tell us about inter-ethnic relationships": http:// www.ons.gov.uk/ons/publications/re-reference-tables.html?edition=tcm\%3A77-365449

It is clear that the Bangladeshi and Sikh groups are overwhelmingly endogamous, whereas there is a material level of inter-marriage for the Chinese and Jewish groups. Gordon's (1964) perspective on this is that these higher levels could only be achieved if the relevant groups were residentially dispersed amongst the wider

3 Note that 2011 data include same-sex civil partnerships in the married column. Note also that ONS has not released information for the Sikh group for 2011, so the table shows data for 2001 for that group. Data for 2001 does exist for the other three groups - it shows that there has been no material change in out-marriage for the Bangladeshi and Jewish groups since 2001, but the proportion of Chinese with non-Chinese spouses has increased by 5 percent from 22 percent; the Sikh proportion for 2011 can be expected to be similar to 2001. 
population, and had become culturally assimilated (see also Waters/Jiménez 2005). In reality, the degree of intermarriage may involve more than residential proximity between the groups and individual concerned, so to what extent is this reflected in the spatial distribution of these groups?

\section{Analysis of Census Distribution Data}

\section{Group Spatial Distribution}

Having set out some of the overall characteristics that may have an influence on shaping the spatial distribution of the groups, their geographic distribution and trajectories are examined in this section. Whenever census data (particularly for small groups) is being analysed spatially, there is always a balance to be struck between data accuracy and quality, and homogeneity of areas being considered. LSOA geography (defined by ONS taking account of consistency of housing type) has been selected. This strikes a balance between small numbers and non-disclosure adjustments affecting OA data, and the potential for MSOA areas to mask within-area variation (see also Catney 2018).

LSOAs ranked by the population of the group under examination can be plotted, and contiguous accumulations or communities can be identified. The method used built on that used by Sapiro (2016) to identify Jewish accumulations using MSOA geography. For the current study it was noted that for three of the groups over 80 percent of their populations can be found in each group's most populous 10 percent of LSOAs. These LSOAs were plotted and geographically contiguous groupings of them were regarded as accumulations. Accumulations for each group that each include at least 1 percent of the group's total England and Wales population have been listed in Table 4. Where there is a strong student presence in an accumulation, a figure excluding students, approximating to the "permanent" group presence in the area, is also shown in the table. Note that as this approach includes all LSOAs with group populations down as far as 8 persons (Jewish) to 19 persons (Chinese), varying the criterion from the 10 percent proportion has no impact on which localities would be listed in Table 4, or materially change their rounded-tothe-nearest-thousand populations.

There is a marked similarity in the hierarchy of accumulations for the Bangladeshi, Jewish, and Sikh groups. Each has one large moderately dense accumulation in the London area, which is the home to a large proportion of the total England and Wales population (noting that the Sikh community has a second equally large congregation in the West Midlands). There are one or two more moderately sized groupings elsewhere in the London area; one or two significant communities outside of London (Birmingham for Bangladeshis, North Manchester area for Jews; Leicester and Coventry for Sikhs), and then a scattering of smaller accumulations. Given the long period of establishment of the Jewish group in Britain, the level of congregation of that group is exceptionally high compared to what might be expected from traditional theory, though this type of pattern for Jewish communities 
Tab. 4: Group accumulations and population (2011)

\begin{tabular}{|c|c|c|}
\hline $\begin{array}{l}\text { Location of } \\
\text { students }\end{array}$ & ulation (and group population it & ousands including/excluding \\
\hline Group & In London area & Elsewhere in England and Wales \\
\hline Bangladeshi & $\begin{array}{l}\text { Tower Hamlets, Newham, } \\
\text { Redbridge, \& Barking (148); } \\
\text { Camden \& Islington W (13); } \\
\text { Haringey (5) }\end{array}$ & $\begin{array}{l}\text { Birmingham \& West Bromwich } \\
\text { (36); Oldham (16); Luton (13); } \\
\text { Bradford (7); Walsall (6); } \\
\text { Manchester (6) }\end{array}$ \\
\hline Chinese & $\begin{array}{l}\text { Westminster, Camden, Islington, } \\
\text { \& Hackney (22/14); Southwark, } \\
\text { Lewisham, Greenwich, \& } \\
\text { Lambeth (19/14); Tower Hamlets } \\
\text { \& Newham (10/8); Barnet }(9 / 7)\end{array}$ & $\begin{array}{l}\text { Manchester \& Salford (13/7); } \\
\text { Birmingham (7/3); Liverpool (5/2) }\end{array}$ \\
\hline Jewish & $\begin{array}{l}\text { Barnet, Hertsmere, Harrow, } \\
\text { Camden and environs (118); } \\
\text { Hackney \& Haringey SE (17); } \\
\text { Redbridge \& Epping Forest (14) }\end{array}$ & $\begin{array}{l}\text { Bury, Salford \& Manchester } \\
\text { N (18); Leeds (5); Trafford, } \\
\text { Stockport, Manchester S, \& } \\
\text { Cheshire East (5); Gateshead } \\
\text { (3/2); Brighton (3) }\end{array}$ \\
\hline Sikh & $\begin{array}{l}\text { Ealing, Hounslow, Hillingdon, } \\
\text { Slough \& environs (90); } \\
\text { Redbridge, Newham, Barking, } \\
\text { \& Epping Forest (27); Bexley \& } \\
\text { Greenwich (6) }\end{array}$ & $\begin{array}{l}\text { Sandwell, Birmingham, Walsall, } \\
\text { Wolverhampton and environs } \\
\text { (98); Leicester, Oadby, \& Blaby } \\
\text { (21); Coventry \& Nuneaton (18); } \\
\text { Gravesham \& Dartford (10); Derby } \\
\text { \& S Derbys (9); Warwick (5); } \\
\text { Leeds (5); Pudsey \& Bradford E (5) }\end{array}$ \\
\hline
\end{tabular}

* shown only if students make up more than 15 percent of population

Note - see text for definition of "accumulation"

Source: Author derived from 2011 census outputs (see text)

(in the UK and elsewhere) has been recognised for a long time (Massarik/Chenkin 1973; Newman 1985; Waterman/Kosmin 1987; Kosmin et al. 1991; Kotler-Berkowitz et al. 2004).

The Jewish group is predominantly focussed in outer suburban areas and the small town/partly-rural hinterland beyond the suburban limit. There is no material presence in the original settlement areas of, for example, the "east end" of London and central Manchester (Williams 1990; Freedman 1992; Endelman 2002). The Sikh group follows a generally similar pattern, but with a continuing presence in inner suburbs in some of the West Midlands authorities, and in the original settlement area in Ealing (London). The Bangladeshi group is very strongly focussed in the Tower Hamlets area of east London (that is, the same settlement area occupied by Jews a century earlier), and adjoining Newham.

The pattern for the Chinese group looks quite different. There are no large area/ large population accumulations, and the student element of accumulations is very significant, particularly away from London, where the focus is frequently on the 
fringe of the inner areas with extensions into the outer suburbs. See Luk (2009) for a more extensive discourse on the distribution of Chinese. There is a much greater scattering of small pockets of Chinese than seen for other groups; Luk (2008) makes reference to Chinese immigrants working in the catering trade deliberately choosing to move away from traditional "Chinatown" areas in order to expand the market and avoid creating an over-supply of Chinese cuisine in a concentrated area.

\section{1 to 2011 changes}

So, what is the trajectory of distribution; where have the 2001 to 2011 changes taken place? The proportion of the population of each LSOA belonging to each of the groups in 2001 and 2011 was compared, and the LSOAs ranked by group proportion change. For each group, the 150 LSOAs (across England and Wales as a whole) where the group's share of the population had increased by the largest percentage (positive change) were identified. Similarly the 150 LSOAs where the share had reduced by the largest proportion (negative change) were also determined. A mapping exercise to display spatial distribution and change has been carried out, and extracts of England and Wales maps showing the London area are shown in Figure 4. To be clear, the maps show those of the 300 largest change LSOAs from England and Wales as a whole that happen to fall in the London area (which, for all groups, includes a large proportion of the 300 ). Hatching on the maps shows areas where the particular group made up more than 6 percent of the 2001 population. This allows the reader to identify unhatched but shaded/coloured areas where the 2001 proportion was relatively low but there has been a large intercensal change. Hatched but unshaded/uncoloured areas where the 2001 proportion was relatively high, but the change between 2001 and 2011 has not been very large, can also be observed.

The pattern of change between 2001 and 2011 (as with the actual distribution) shows a remarkable degree of similarity for the Bangladeshi, Jewish and Sikh groups. In terms of the principal focus of the Bangladeshi group in east London, there is a reduced concentration in parts of the most densely populated area. An increase in congregation in a central part of the accumulation has occurred with a noticeable extension into more suburban areas that were not part of the 2001 "heartland". There is thus both a re-focussing within the main area of settlement, and a strong movement into "new" areas outwards from the centre of London suburbanisation (see Farrell 2016 for an American perspective on minority group suburbanisation). In addition this is combined with a noticeable loss of population share in the smaller London communities and scattered areas elsewhere. The Jewish and Sikh groups repeat this pattern, though in those cases the extension is into semi-rural areas and might be better described as counter-urbanisation rather than suburbanisation.

There is no noticeable suburbanisation pattern for the Chinese community. Insofar as the London area is concerned there is a refocussing into two inner city areas. This is accompanied by a loss in group proportion in almost every small pocket across the rest of the London area - almost a centralisation process, potentially dis- 
Fig. 4: Change in distribution 2001 to 2011 at LSOA level

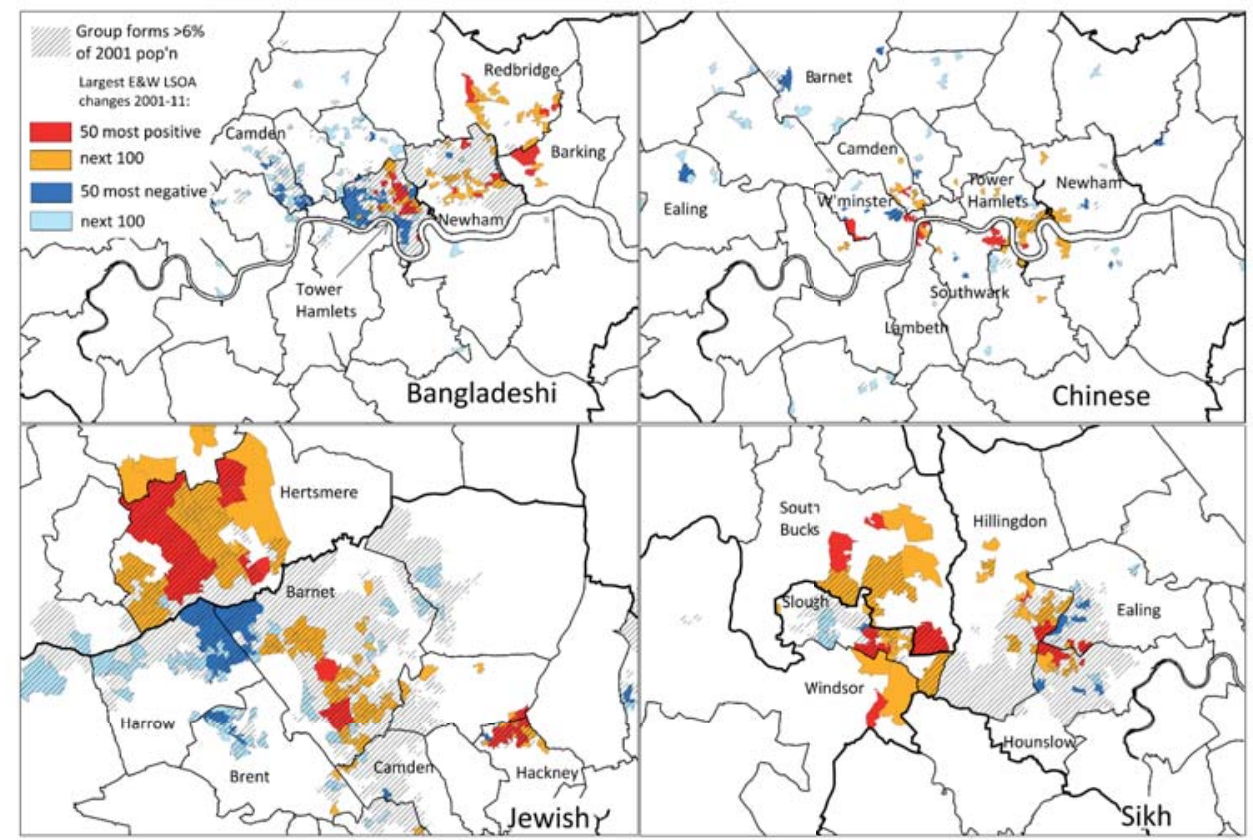

Note: see main text for explanation of the key

Source: Author derived based on analysis of 2001 and 2011 census data

torted through the dominance of the impact of students in some areas. Indeed, the student impact in provincial areas is much more apparent - with strong growth in university/student areas of the major cities, and (as in London) a loss in proportion in small suburban clusters.

Qualitatively therefore, some clear patterns of change can be observed, but can a closer investigation of the characteristics of shrinking and expanding areas provide a clearer explanation of these changes? That is, does heterogeneity within the groups help us to understand the patterns in a better way than a focus on distribution indices or overarching terms such as suburbanisation?

As already described, the 34,000 LSOAs have been ranked by the 2001 to 2011 change in proportion of the LSOA's population that belongs to each group under examination. This showed that material change is limited to around 400 LSOAs at each end of the spectrum. Table 5 provides an overview of the characteristics of areas that have had an increase in group proportion over the 10 year period (gaining/ growth areas), and those where there has been a reduction (contracting/shrinking areas), based on the two groups of 400 LSOAs relevant to each group.

If the age profile for an area or group in 2001 is artificially aged by 10 years and then compared with the actual 2011 profile (for example by "lifting" the 2001 age pyramid by 10 years and overlaying on top of the 2011 pyramid - see Simpson/Jivraj 
2015: 43-45) then the differences will represent the impact of births, deaths, and migration over the intercensal period. More specifically, the number of 0-9 year olds in 2011 will represent births over the intercensal period (subject to some migration, depending on the scale of migration for their parents' age band). Differences in profiles between the ages of 10 and 59 will represent net migration (subject to a small number of deaths); and differences over the age of 60 will be largely representative of deaths (and some older age migrations) (Ballard 2004; Simpson/Jivraj 2015). The age band population data that ONS has made available for ethnic and religion based groups in the 2001 and 2011 censuses at LSOA level allows differences in the profiles to be split at age 10 and 60 . It has been necessary to assume that the age 60+ difference all relates to deaths; however, except for the Jewish group, the proportion in that age band for the cultural groups is very small So, natural change has been determined by subtracting the over 60 difference from the number of 2011 0-9 year olds, and the age 10-59 difference has been used to represent migration. Fortunately, for all groups, the difference between the calculated natural change and migration has been far greater than would be nullified by errors caused by the simplifications that have had to be made. The table is thus able to indicate whether migration (denoted as "mig") or natural change ("nat") is the greater source of intercensal population change for each group.

There are some common characteristics for all four groups: contracting areas have a higher proportion of people with poor health than gaining areas and (not shown in the table) this disparity has increased over the 10 year period. Given that group proportion is reducing in these areas, it is unlikely that the movement into the area of people with poor health is a significant factor. The conclusion to be drawn is that people with poorer health are less likely to move home and get "left behind" in areas of group shrinkage. Indeed their health may suffer through increasing isolation from other members of their group (Smith/Easterlow 2005). Darlington et al. (2015) provide a discussion on the complexities of unravelling the relationship between health and internal migration.

For three of the groups, areas of growth have a higher proportion of 0-15 year olds and a lower proportion of those aged 75 than do contracting areas; again (not shown in the table) the disparity has increased in the intercensal period. This agerelated aspect to changes in distribution was also found in America (Winkler/Johnson 2016). As might be expected, areas with an increasing group proportion benefit from positive natural change (excess of births over deaths), whereas the opposite situation applies to shrinking areas, though for most groups migration (whether international or internal) has a larger impact on the outcome. The Chinese figures are heavily influenced by the very high student presence in growth areas (71 percent); nevertheless the small levels of natural change are also positive for growth areas and negative for shrinking areas.

There is a marked difference in population density between the groups of LSOAs for Sikhs - reflecting the urban locations for the shrinking areas and the suburban gaining localities. There is no differential for the (suburban) Jewish group, but the Bangladeshi figures reflect the very dense urban locality of the contracting areas and the more typical urban value for growth areas. It is only the Sikh areas that 


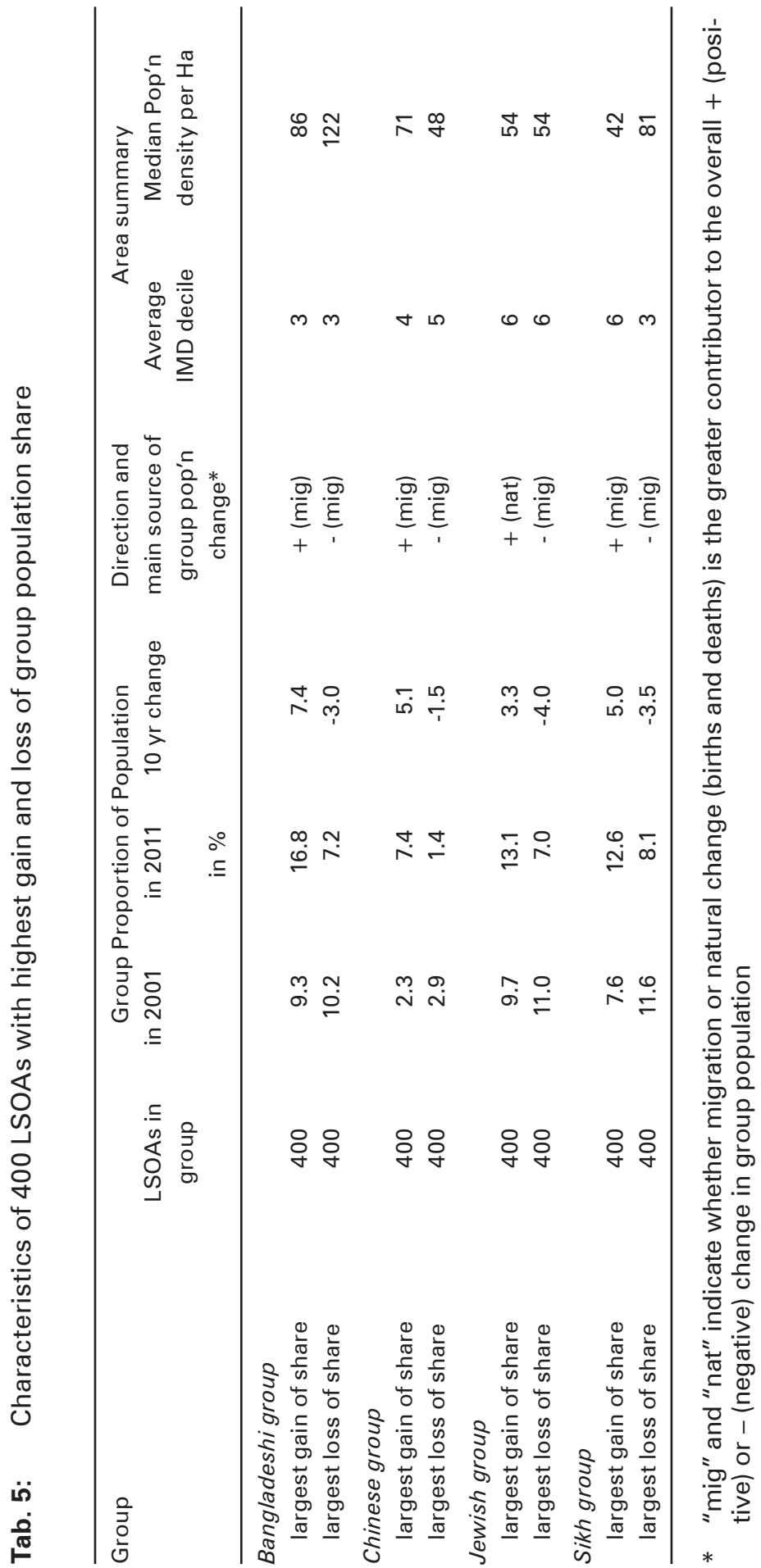




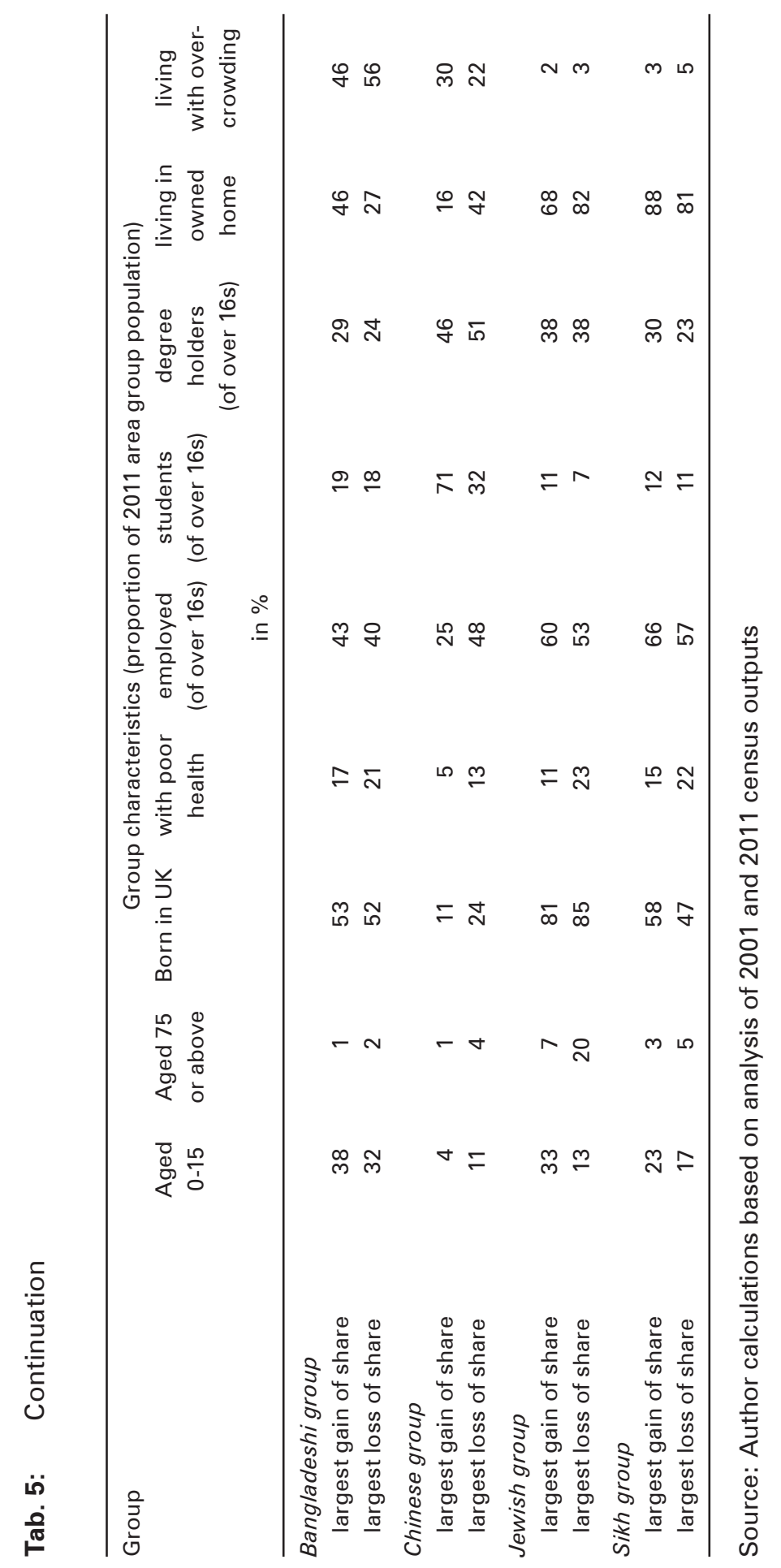


show a marked difference between the average decile of deprivation in which the groups of LSOAs lie - with the growth areas on average 3 deciles less deprived than the shrinking areas. This figure is actually exceeded by the white British group (not shown in the table). This should be compared with the Swedish picture where there is an apparent inability of ethnic minority groups located in poorer neighbourhoods in childhood to relocate to better areas in adulthood (Gustafsson et al. 2017).

Whilst this summary provides an interesting overview, to address the influence of heterogeneity of individual and area characteristics, we need to examine whether these patterns apply consistently across the actual localities where reducing and increasing population shares have been found. Table 6 summarises the same characteristics, area by area. The areas have been named after the main local authority involved, though they are defined in terms of groups of contiguous LSOAs (annotated in the table) where there is shrinkage or expansion. For reasons of space, only the largest areas are shown.

In 2001 and 2011 the more suburban of the Bangladeshi increasing share areas had a lower proportions of 0-15 year olds, higher proportion of people over 50, degree holders, employed persons, and home owners and less over-crowding than Bangladeshis living in other growth areas. Migration has a more important role in growth areas than is the case elsewhere. Indeed, there are differences between areas where natural change has been the larger contributor to expansion. They are generally located in areas of highest deprivation, and where the proportion of 0-15 year olds exceeds 40 percent, and proportions in employment and good health are lower.

Such is the dominance of the student impact on the Chinese group that only two expanding areas (one is shown in the table) could be located that were not dominated by students, though even in these places students make up a disproportionate element. Most of the student-dominated expanding areas have seen a five- to ten-fold increase in the number of Chinese residents over the decade, and also large increases in the proportion made up by students. Their differentiating characteristic is thus the level of popularity of their universities with (international) Chinese students. And as the Chinese group is relatively scattered, only one small group of 5 LSOAs that encompassed a reducing proportion could be found.

There are clear differences between some of the gaining Jewish areas. Those with the largest changes in population share in the decade are located in areas of fairly high deprivation, have extremely high proportions of 0-15 year olds, low levels (compared with the Jewish group overall) of older people, low levels of poor health, and generally low levels of degree holders and home ownership. Natural change is a more important source of population change than migration. These areas are known to be the home of Britain's strictly orthodox Jewish communities, which demonstrate a high level of fertility (Graham 2013; Staetsky/Boyd 2015). The other growth areas are located in areas of lower deprivation, and whilst they feature above average (rather than very high) proportions of 0-15 year olds and larger proportions of older people than the first three areas, adults in these areas are more likely to be employed, hold a degree, and be home-owners. Unlike the other small 


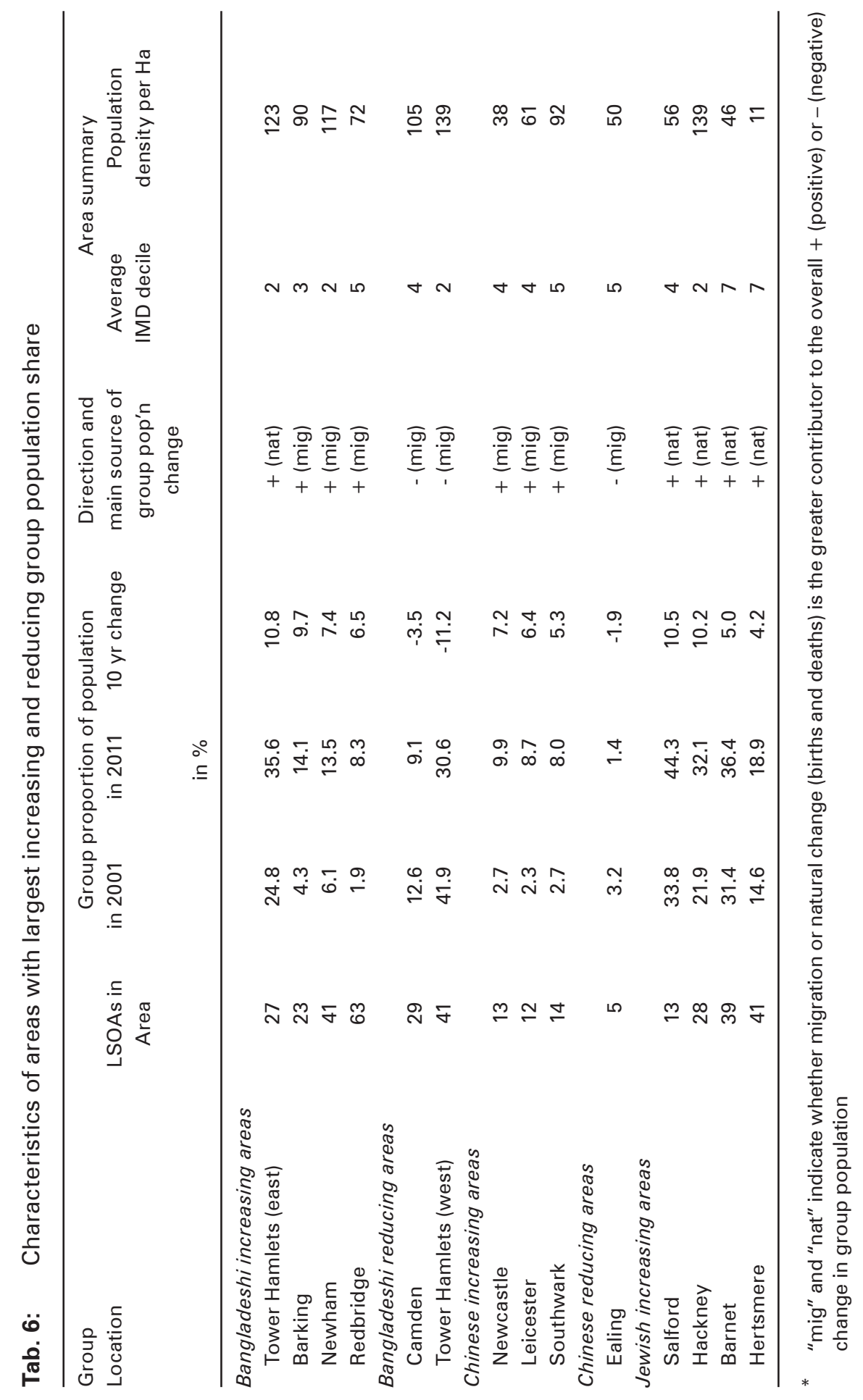




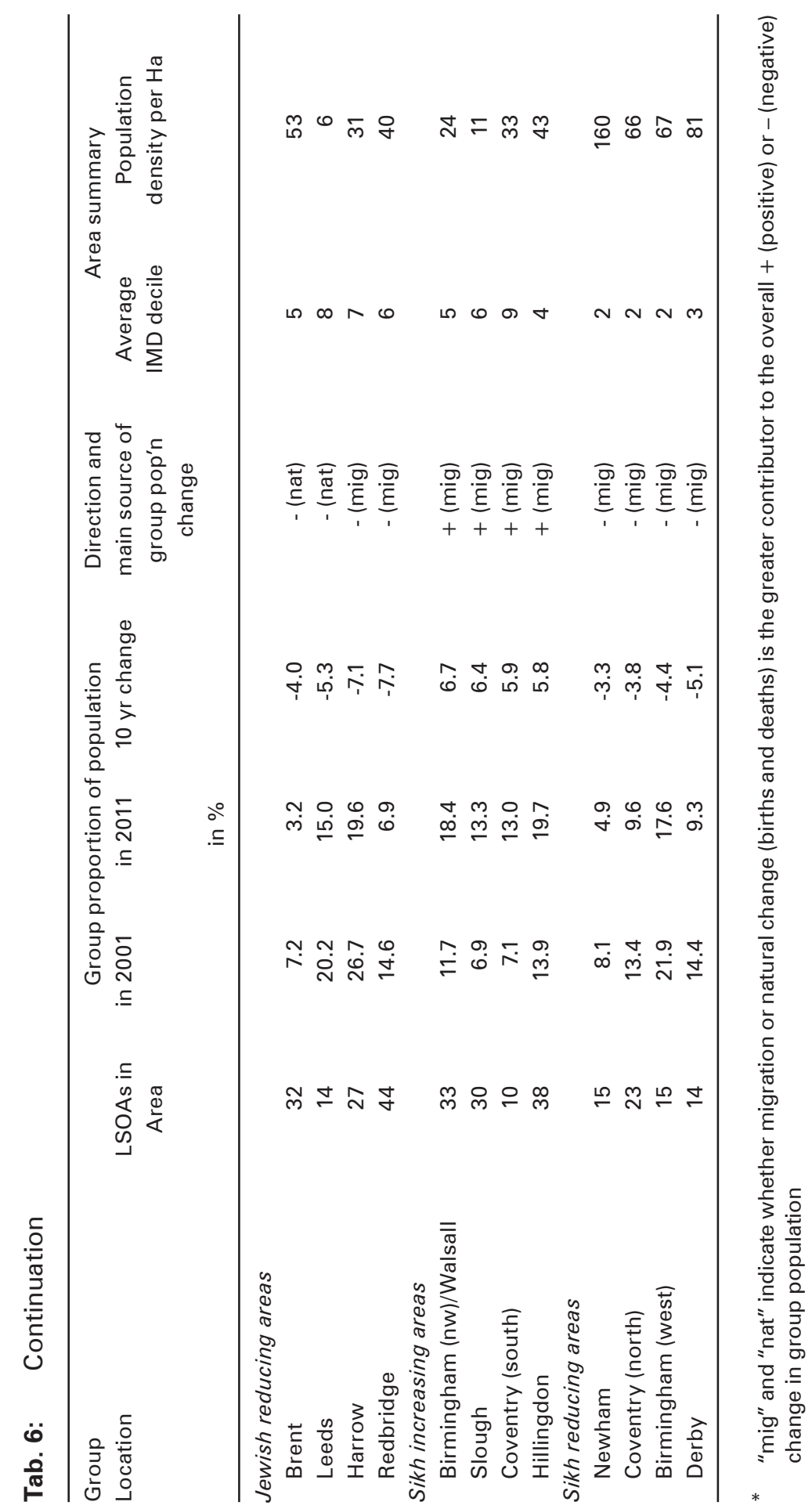




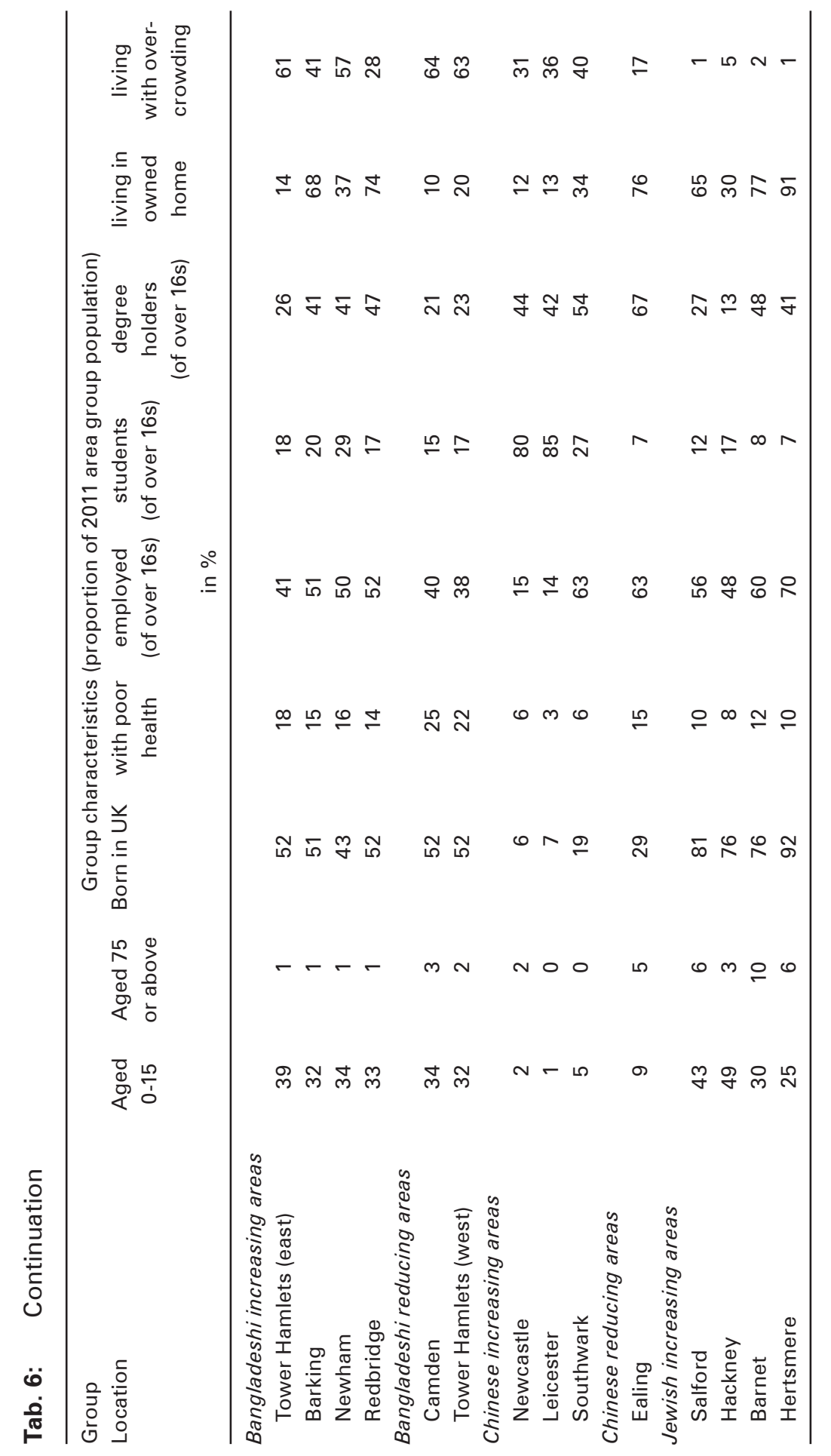




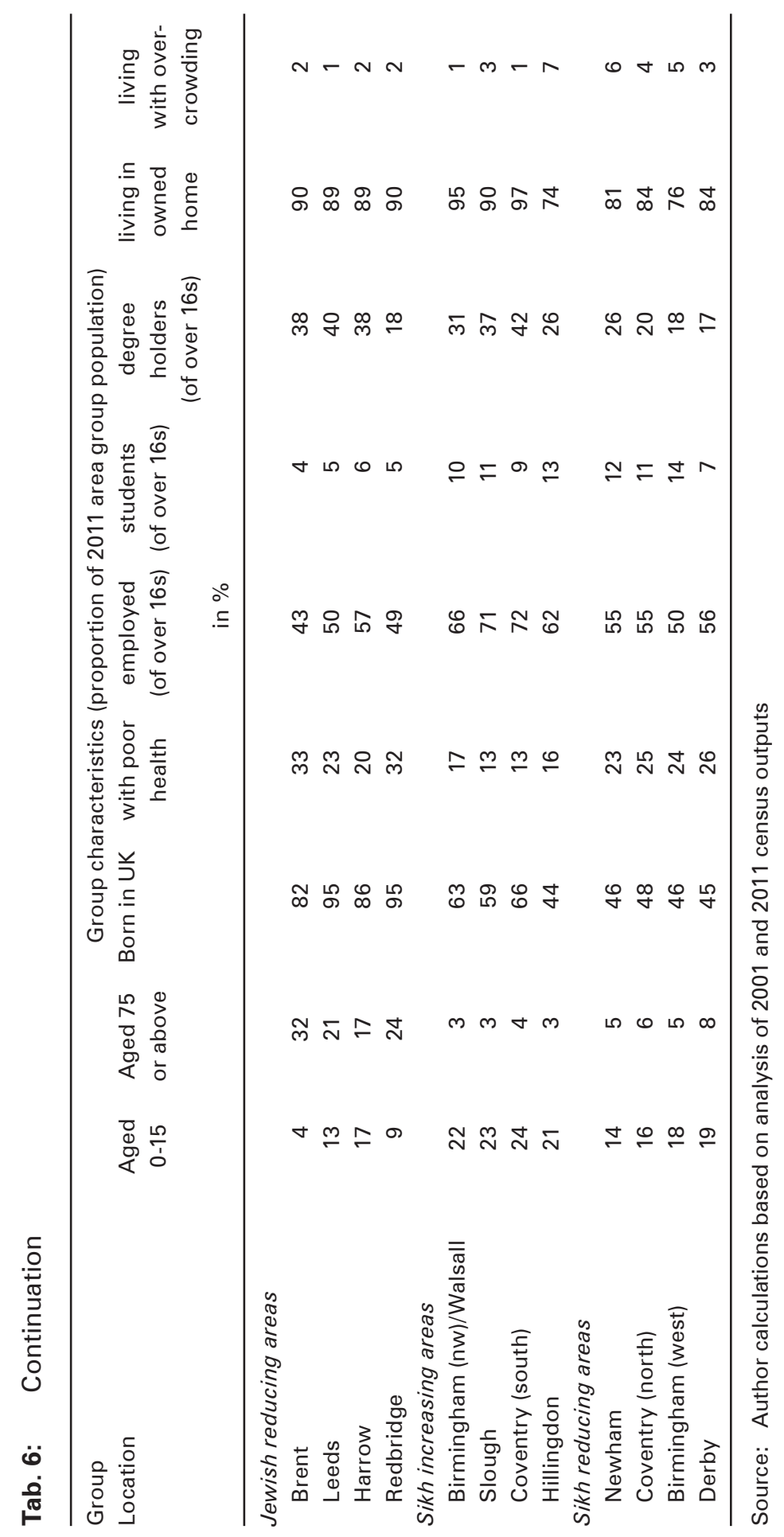


cultural groups, for Jews, natural change is a more influential source of population change than migration for all the gaining and most of the contracting areas.

The Sikh analysis includes a number of pairs of proximate localities between the increasing and reducing areas, primarily in the Midlands, where the contracting area has a high level of deprivation and a higher population density, and the growth area a lower or much lower level. This implies movement by those with improving socioeconomic standing from one area to the other. The growing areas also benefit from positive natural change reflected in higher proportions of 0-15 year olds, which may contribute to the lower level of poor health in the expanding areas.

\section{Discussion and Conclusions}

Some global characteristics of the groups, linked to traditional theories, have been explored. This has identified some similarities, but also some quite distinct differences, between the groups. Have these differences been reflected in their spatial distribution? The longevity of the Jewish group's presence in Britain is reflected in its almost complete absence from its areas of original settlement, whereas the Bangladeshi group is still much focussed in its settlement areas and the Sikh group maintains a presence in its original areas. The broadly similar scale of clustering found in these three groups means that, contrary to traditional theory, length of presence has not led to a dispersed pattern. Moreover, the link between intermarriage levels (which vary greatly between these three groups) and level of dispersal (which does not) is weak. Socio-economic status (and more specifically, professional and managerial positions) has a link with location of residence, with groups with higher proportions of employment at these levels being found in areas in less deprived IMD deciles. Thus, if we review some key elements of traditional theories in the light of this study's findings, we can conclude that socio-economic progress has led to relocation of groups away from their initial settlement areas towards more sought-after residential localities. However, such moves have not led to widespread dispersal (for three of the groups), nor (for the Jewish group) has intermarriage remained limited due to a lack of residential dispersal.

There are some broad similarities between the groups in areas where the proportion of a group has reduced between 2001 and 2011, and another set of broadly shared characteristics for areas that have expanded. Two key finding are, firstly, that areas where the concentration of a group has been relatively high, but has reduced, are locations of worsening health inequality. Secondly, areas where the proportional Sikh presence is above average and increasing actually demonstrate reduced socio-economic disadvantage. When an index-based approach is used, sub-areas of the study area that demonstrate a group population proportion equal to the average for the study area as a whole generally contribute a zero value to the index. Larger values are contributed by areas where the group proportion varies more from the overall average. If two time periods/censuses are being compared, then areas which have moved closer to the study area average would be making less of a contribution to the index, and this reducing value and would be considered to represent an 
"improving" result. Conversely, areas moving further away from the average value between the censuses would be demonstrating an increasing contribution to the index value and would be regarded as a "worsening" result. Thus in the case of the two types of area described at the start of this paragraph, an index-based approach would conclude that the first type was an improving situation (and thus warranting reduced attention) and the second type a worsening scenario. That is, an indexbased approach can lead to misleading conclusions in targeting disadvantage.

When the analysis explores individual areas where the group population proportion has materially increased or reduced, not only are there many differences between the cultural groups, but there is much reduced consistency of characteristics within each group. However, there is a degree of consistency insofar as the relative importance of migration (whether international or internal) and natural change is concerned. Despite the greater presence of older people in the Jewish group compared with the other groups under examination (and its likely negative impact on natural change), positive natural change (rather than migration) is the main driving force in expanding Jewish areas. Conversely, despite the positive natural change overall reflected in the high proportion of 0-15 year olds in the other groups (particularly the Bangladeshi group) migration is the more important element in explaining changed group proportion in increasing areas for those groups. Thus, particularly for areas where group proportion has increased, the more important element is at odds with what might be expected from the overall age profile of the group.

The Chinese group is quite different to the other three groups that have been examined. Whilst the very high presence of international students within that group creates a distinctive pattern to that group's distribution and the large rise in student numbers over the decade overwhelms the pattern of change, it does not explain all the differences.

Levels of congregation of (non-student) members of the Chinese group are very low. Peach notes that "urban concentration allows the groups to pass the threshold size at which ethnic shops and religious institutions can be maintained and the proximity to members of the groups that allows the language and norms of the groups to be maintained" (Peach 1996: 386). This is reflected in the distribution found for three of our groups, but not the Chinese. So why might that be the case? There could well be a religion element to this. By definition, of course, there is a religious commonality within the Jewish and Sikh groups, though the degree of actual religiosity may vary (Graham et al. 2014), and census outputs indicate that 90 percent of Bangladeshis described themselves as Muslim (and only 1 percent had "No religion"). The Chinese group, on the other hand, includes 56 percent who indicated that they had "No religion"; the next largest group (20 percent) were Christians. Neither of these groups requires residential concentration. Additionally, at one of end of the scale, the majority of Bangladeshi early immigrants originated in a relatively compact area of Bangladesh (Sylhet) and many later immigrants have family connections with the earlier arrivals (Ballard 2004). In contrast, the origin of Chinese immigrants has evolved over recent decades. Initially, the arrivals were lowly qualified residents of rural Hong Kong; more recent immigrants came from a much wider 
section of south-east Asia. The most recent arrivals have been highly qualified (Luk $2008,2009)$. There is thus a large inherent heterogeneity in the Chinese group.

The influence of the different elements of the benefit of congregation clearly differ between the groups, and no one over-arching explanation for their current spatial distribution and its trajectory can be found. Indeed, the migration element of distribution appears to embody a tension between suburbanisation/counter-urbanisation "fuelled" by socio-economic progress, and a desire for group congregation. The conclusion is that not only does heterogeneity between the groups confound any attempt to produce a "model" of spatial distribution, but heterogeneity within each group means that producing any form of understanding of, or explanation for, the trajectory of distribution requires the examination of data at a detailed level, and is beyond the scope of global indices. In addition to presenting such information for previously studied ethnic groups, the paper has presented, for the first time, detailed analysis for two religion-based groups.

The key message of this research is that to achieve a full understanding of $\mathrm{mi}$ nority group spatial distribution, investigation at a fine geographic level is required. More importantly, full account of the personal, household, and community characteristics of those involved is essential, rather than placing too much reliance on indices and other measures that underplay the issue of heterogeneity within groups. Indeed, by taking proper account of group heterogeneity in analysing minority group spatial distribution, population analysts can better assist policy makers to spatially target health, education, training, and other social programmes and, as a consequence, address issues of segregation, disadvantage, and cultural diversity.

\section{Acknowledgement}

All census data and mapping used in this paper are Crown Copyright and reproduced or adapted from data from ONS (the Office for National Statistics) licensed under the Open Government Licence v.2.0. 2011 census tables can be accessed via http://www.nomisweb.co.uk/census/2011/data_finder; 2001 tables can be accessed via http://www.nomisweb.co.uk/home/census2001.asp; and underlying ONS mapping via https://geoportal.statistics.gov.uk/geoportal/catalog/main/home.page. The 2011 safeguarded microdata were made available via the UK Data Service and accessed under the terms of its End User Licence.

\section{References}

Ananta, Aris et al. 2015: Demography of Indonesia's ethnicity. Singapore: Institute of Southeast Asian Studies Publishing.

Andersson, Eva K. et al. 2018: A Comparative Study of Segregation Patterns in Belgium, Denmark, the Netherlands and Sweden: Neighbourhood Concentration and Representation of Non-European Migrants. In: European Journal of Population 34,2: 251275 [doi: 10.1007/s10680-018-9481-5]. 
Ãslund, Olof; Skans, Oskar N. 2010: Will I see you at work? Ethnic workplace segregation in Sweden, 1985-2002. In: Industrial \& labor relations review 63,3: 471-493 [doi: 10.1177/001979391006300306].

Bailey, Nick 2012: How spatial segregation changes over time: sorting out the sorting processes. In: Environment and Planning A 44,3: 705-722 [doi: 10.1068/a44330].

Ballard, Roger 2004: The current demographic characteristics of the South Asian presence in Britain: an analysis of the results of the 2001 census. Centre for Applied South Asian Studies: University of Manchester.

Blaikie, Norman W. H. 2000: Designing social research: the logic of anticipation. Malden: Polity Press.

Bolt, Gideon 2009: Combating residential segregation of ethnic minorities in European cities. In: Journal of Housing and the Built Environment 24,4 397 [doi: 10.1007/s10901009-9163-z].

Bouma, Gary D.; Hughes, Philip J. 2014: Using census data in the management of religious diversity: an Australian case study. In: Religion 44,3: 434-452 [doi: 10.1080/0048721X.2014.903639].

Brasz, Chaya 2001: After the Shoah: Continuity and change in the postwar Jewish community of the Netherlands. In: Jewish History 15,2: 149-168 [doi: 10.1023/A:1011036707897].

BSR Team 2014: British Sikh Report 2014: An insight into the British Sikh community: BSR Team.

Catney, Gemma 2016: The changing geographies of ethnic diversity in England and Wales, 1991-2011. In: Population, Space and Place 22,8: 750-765 [doi: 10.1002/ psp.1954].

Catney, Gemma 2017: Towards an enhanced understanding of ethnic group geographies using measures of clustering and unevenness. In: Geographical Journal 183,1: 71-83 [doi: 10.1111/geoj.12162].

Catney, Gemma 2018: The complex geographies of ethnic residential segregation: Using spatial and local measures to explore scale-dependency and spatial relationships. In: Transactions of the Institute of British Geographers 43,1: 137-152 [doi: 10.1111/ tran.12209].

Clark, William A. V. et al. 2015: A Multiscalar Analysis of Neighborhood Composition in Los Angeles, 2000-2010: A Location-Based Approach to Segregation and Diversity. In: Annals of the Association of American Geographers 105,6: 1260-1284 [doi: 10.1080/00045608.2015.1072790].

Cortese, Charles F. et al. 1976: Further Considerations on the Methodological Analysis of Segregation Indices. In: American Sociological Review 41,4: 630-637.

Darlington, Fran; Norman, Paul; Gould, Myles 2015: Health and Internal Migration. In: Smith, Darren P.; Finney, Nissa; Walford, Nigel (Eds.): Internal Migration: Geographical Perspectives and Processes. Farnham: Ashgate: 113-128 [doi: 10.4324/9781315589275].

DCLG 2011: Neighbourhoods statistical release: The English indices of deprivation 2010 London: DCLG.

Dhalmann, Hanna; Vilkama, Katja 2009: Housing policy and the ethnic mix in Helsinki, Finland: perceptions of city officials and Somali immigrants. In: Journal of Housing \& the Built Environment 24,4: 423-439 [doi: 10.1007/s10901-009-9159-8].

Duncan, Otis D.; Duncan, Beverly 1955: A methodological analysis of segregation indexes. In: American Sociological Review 20,2: 210-217 [doi: 10.2307/2088328]. 
Dunn, Kevin. M. 1998: Rethinking ethnic concentration: The case of Cabramatta, Sydney. In: Urban Studies 35,3: 503-527.

Eade, John T.; Vamplew, Tim; Peach, Ceri 1996: The Bangladeshis: the encapsulated community. In: Peach, Ceri (Ed.): Ethnicity in the 1991 census (Vol. 2, ). London: HMSO: 150-160.

Ehrkamp, Patricia 2005: Placing identities: Transnational practices and local attachments of Turkish immigrants in Germany. In: Journal of Ethnic and Migration Studies 31,2: 345-364 [doi: 10.1080/1369183042000339963].

Endelman, Todd M. 2002: The Jews of Britain, 1656 to 2000. University of California Press

Farrell, Chad R. 2016: Immigrant suburbanisation and the shifting geographic structure of metropolitan segregation in the United States. In: Urban Studies 53,1: 57-76 [doi: 10.1177/0042098014558537].

Finney, Nissa; Simpson, Ludi 2008: Internal migration and ethnic groups: evidence for Britain from the 2001 Census. In: Population, Space and Place 14,2: 63-83 [doi: 10.1002/psp.481].

Fowler, Christopher Stiles 2016: Segregation as a multiscalar phenomenon and its implications for neighborhood-scale research: the case of South Seattle 1990-2010. In: Urban Geography 37,1: 1-25 [doi: 10.1080/02723638.2015.1043775].

Freedman, Murray 1992: Leeds Jewry: The First Hundred Years. York: Jewish Historical Society of England: Leeds Branch.

Gershman, Boris; Rivera, Diego 2018: Subnational diversity in Sub-Saharan Africa: Insights from a new dataset. In: Journal of Development Economics 133: 231-263 [doi: 10.1016/j.jdeveco.2018.01.003].

Gordon, Milton M. 1964: Assimilation in American life : the role of race, religion, and national origins: New York : Oxford University Press.

Graham, David 2013: 2011 Census Results (E\&W): A tale of two Jewish populations. London: Institute for Jewish Policy Research.

Graham, David; Staetsky, L. Daniel; Boyd, Jonathan 2014: Jews in the United Kingdom in 2013: Preliminary findings from the national Jewish community survey. London: Institute for Jewish Policy Research.

Graham, David; Waterman, Stanley 2005: Underenumeration of the Jewish population in the UK 2001 Census. In: Population, Space and Place 11,2: 89-102 [doi: 10.1002/ psp.362].

Gustafsson, Björn; Katz, Katarina; Osterberg, Torun 2017: Residential segregation from generation to generation: Intergenerational association in socio-spatial context among visible minorities and the majority population in metropolitan Sweden. In: Population Space \& Place 23,4: 13 [doi: 10.1002/psp.2028].

Harris, Richard 2014: Measuring changing ethnic separations in England: A spatial discontinuity approach. In: Environment and Planning A 46,9: 2243-2261 [doi: 10.1068/ a130021p].

Harris, Richard; Owen, Dewi 2018: Implementing a Multilevel Index of Dissimilarity in R with a case study of the changing scales of residential ethnic segregation in England and Wales. In: Environment and Planning B: Urban Analytics and City Science 45,6: 1003-1021 [doi: 10.1177/2399808317748328]. 
Hennerdal, Pontus; Nielsen, Michael Meinild 2017: A Multiscalar Approach for Identifying Clusters and Segregation Patterns That Avoids the Modifiable Areal Unit Problem. In: Annals of the American Association of Geographers 107,3: 555-574 [doi: 10.1080/24694452.2016.1261685].

Hills, John et al. 2010: An anatomy of economic inequality in the UK: Report of the national equality panel. London: Centre for Analysis of Social Exclusion, LSE.

Holmqvist, Emma; Bergsten, Zara 2009: Swedish social mix policy: a general policy without an explicit ethnic focus. In: Journal of Housing \& the Built Environment 24,4: 477-490.

Iceland, John; Nelson, Kyle Anne 2008: Hispanic segregation in metropolitan America: Exploring the multiple forms of spatial assimilation. In: American Sociological Review, 73(5), 741-765 [doi: 10.1177/000312240807300503].

Jivraj, Stephen; Simpson, Ludi 2015: Ethnic identity and inequalities in Britain: the dynamics of diversity. Bristol: Policy Press.

Jones, Kelvyn et al. 2015: Ethnic Residential Segregation: A Multilevel, Multigroup, Multiscale Approach Exemplified by London in 2011. In: Demography 52,6: 1995-2019 [doi: 10.1007/s13524-015-0430-1].

Johnston, Ron et al. 2004: Scale, factor analyses, and neighborhood effects. In: Geographical Analysis 36,4: 350-368 [doi: 10.1111/j.1538-4632.2004.tb01141.x].

Johnston, Ron et al. 2016: Macro-scale stability with micro-scale diversity: modelling changing ethnic minority residential segregation - London 2001-2011. In: Transactions of the Institute of British Geographers 41,4: 389-402 [doi: 10.1111/tran.12142].

Johnston, Ron; Poulsen, Michael; Forrest, James 2015: Increasing diversity within increasing diversity: the changing ethnic composition of London's neighbourhoods, 2001-2011. In: Population Space \& Place 21,1: 38-53 [doi: 10.1002/psp.1838].

Johnston, Ron; Poulsen, Michael; Forrest, James 2016: Ethnic Residential Patterns in Urban England and Wales, 2001-2011: A System-Wide Analysis. In: Tijdschrift voor Economische en Sociale Geografie 107,1: 1-15 [doi: 10.1111/tesg.12128].

Kempen, Ronald van; Bolt, Gideon 2009: Social cohesion, social mix, and urban policies in the Netherlands. In: Journal of Housing \& the Built Environment 24,4: 457-475.

Kosmin, Barry A. et al. 1991: Highlights of the CJF 1990 national Jewish population survey: Council of Jewish Federations New York.

Kotler-Berkowitz, Laurence et al. 2004: The national Jewish population survey 2000 01: strength, challenge and diversity in the American Jewish population. New York: United Jewish Communities.

Luk, Wai-ki E. 2008: Chinatown in Britain: Diffusions and concentrations of the British new wave Chinese immigration. New York: Cambria Press.

Luk, Wai-ki E. 2009: Chinese ethnic settlements in Britain: spatial meanings of an orderly distribution, 1981-2001. In: Journal of Ethnic \& Migration Studies 35,4: 575-599 [doi: 10.1080/13691830902765137].

Lymperopoulou, Kitty 2013: The area determinants of the location choices of new immigrants in England. In: Environment and Planning A 45,3: 575-592 [doi: 10.1068/ a44673].

Massarik, Fred; Chenkin, Alvin 1973: United States national Jewish population study: A first report. In: The American Jewish Year Book: 264-269.

Massey, Douglas S. 1985: Ethnic residential segregation: a theoretical synthesis and empirical review. In: Sociology and Social Research 69,3: 315-350. 
Massey, Douglas S.; Denton, Nancy A. 1988: The dimensions of residential segregation. In: Social Forces 67,2: 281-315 [doi: 10.1093/sf/67.2.281].

Münch, Sybille 2009: "It's all in the mix": constructing ethnic segregation as a social problem in Germany. In: Journal of Housing \& the Built Environment 24,4: 441-455 [doi: 10.1007/s10901-009-9160-2].

Nagel, Caroline R. 2009: Rethinking geographies of assimilation. In: Professional Geographer 61,3: 400-407 [doi: 10.1080/00330120902941753].

Newman, David 1985: Integration and ethnic spatial concentration: The changing distribution of the Anglo-Jewish community. In: Transactions of the Institute of British Geographers 10,3: 360-376.

ONS 2009: 2011 Census Data Quality Assurance Strategy. Office for National Statistics.

ONS 2011: 2011 Census: Household Questionnaire: England. Office for National Statistics.

ONS 2012: Item Non-response, Item Deterministic Editing and Item Imputation. Newport: Office for National Statistics.

ONS 2014: 2011 census microdata individual safeguarded samples - user guide. London: Office for National Statistics.

Openshaw, Stan 1984: Concepts and techniques in modern geography number 38: the modifiable areal unit problem. Norwich: Geo Books.

Östh, John; Clark, William A. V.; Malmberg, Bo 2015: Measuring the Scale of Segregation Using k-Nearest Neighbor Aggregates. In: Geographical Analysis 47,1: 34-49 [doi: 10.1111/gean.12053].

Park, Robert E. 1926: The urban community as a spatial pattern and a moral order. In: Burgess, Ernest W. (Ed.): The urban community. Chicago: University of Chicago Press: 3-18.

Peach, Ceri 1996: Good segregation, bad segregation. In: Planning Perspectives 11,4: 379-398 [doi: 10.1080/026654396364817].

Peach, Ceri; Gale, Richard 2003: Muslims, Hindus, and Sikhs in the new religious landscape of England. In: Geographical Review 93,4: 469-490 [doi: 10.1111/j.19310846.2003.tb00043.x].

Petrović, Ana; van Ham, Marten; Manley, David 2018: Multiscale Measures of Population: Within- and between-City Variation in Exposure to the Sociospatial Context. In: Annals of the American Association of Geographers 108,4: 1057-1074 [doi: 10.1080/24694452.2017.1411245].

Phillips, Deborah; Davis, Cathy; Ratcliffe, Peter 2007: British Asian narratives of urban space. In: Transactions of the Institute of British Geographers 32,2: 217-234.

Portes, Alejandro; Zhou, Min 1993: The new second generation: segmented assimilation and its variants. In: Annals of the American Academy of Political and Social Science 530,1: 74-96 [doi: 10.1177/0002716293530001006].

Přidalová, Ivana; Hasman, Jiři 2018: Immigrant groups and the local environment: sociospatial differentiation in Czech metropolitan areas. In: Geografisk Tidsskrift-Danish Journal of Geography 118,1: 72-87 [doi: 10.1080/00167223.2017.1370382].

Reardon, Sean F. et al. 2008: The Geographic Scale of Metropolitan Racial Segregation. In: Demography 45,3: 489-514 [doi: 10.1353/dem.0.0019].

Rees, Philip et al. 2017: The impact of internal migration on population redistribution: an international comparison. In: Population Space \& Place 23,6: e2036 [doi: 10.1002/ psp.2036]. 
Rees, Philip; Butt, Faisal 2004: Ethnic change and diversity in England, 1981-2001. In: Area 36,2: 174-186 [doi: 10.1111/j.0004-0894.2004.00213.x].

Rees, Philip; Phillips, Deborah; Medway, Dominic 1995: The socioeconomic geography of ethnic groups in two northern British cities. In: Environment and Planning A 27,4: 557-591 [doi: 10.1068/a270557].

Rees, Philip; Wohland, Pia; Norman, Paul 2013: The demographic drivers of future ethnic group populations for UK local areas 2001-2051. In: Geographical Journal 179,1: 44-60 [doi: 10.1111/j.1475-4959.2012.00471.x].

Rugh, Jacob S.; Massey, Douglas S. 2010: Racial segregation and the American foreclosure crisis. In: American Sociological Review 75,5: 629-651 [doi: 10.1177/0003122410380868].

Sapiro, Philip 2016: Beyond the strictly orthodox/mainstream divide: Applying geodemographic analysis to a small nationwide sub-population. In: Computers, Environment and Urban Systems 56: 36-47 [doi: 10.1016/j.compenvurbsys.2015.11.004].

Schmool, Marlena; Cohen, Frances. A. 1998: A profile of British Jewry: Patterns and trends at the turn of a century. Board of Deputies of British Jews London.

Shon, Jean-Louis Pan Ké 2010: The ambivalent nature of ethnic segregation in France's disadvantaged neighbourhoods. In: Urban Studies 47,8: 1603-1623 [doi: 10.1177/0042098009356123].

Simpson, Ludi 2007: Ghettos of the Mind: The Empirical Behaviour of Indices of Segregation and Diversity. In: Journal of the Royal Statistical Society A 170,2: 405-424 [doi: 10.1111/j.1467-985X.2007.00465.x].

Simpson, Ludi 2012: More segregation or more mixing? The Dynamics of Diversity: evidence from the 2011 Census. Manchester: Centre on Dynamics of Ethnicity (CoDE).

Simpson, Ludi; Finney, Nissa 2009: Spatial patterns of internal migration: evidence for ethnic groups in Britain. In: Population, Space and Place 15,1: $37-56$ [doi: 10.1002/ psp.497].

Simpson, Ludi; Jivraj, Stephen 2015: Why has ethnic diversity grown? In: Jivraj, Stephen; Simpson, Ludi (Eds.): Ethnic Identity and Inequalities in Britain: The Dynamics of Diversity. Bristol: Policy Press: 33-48.

Smith, Susan J.; Easterlow, Donna 2005: The strange geography of health inequalities. In: Transactions of the Institute of British Geographers 30,2: 173-190 [doi: 10.1111/j.1475-5661.2005.00159.x].

Staetsky, L. Daniel; Boyd, Jonathan 2015: Strictly orthodox rising: what the demography of British Jews tells us about the future of the community. London: Institute for Jewish Policy Research.

Taeuber, Karl E.; Taeuber, Alma F. 1976: A practitioner's perspective on the index of dissimilarity. In: American Sociological Review 41,5: 884-889 [doi: 10.2307/2094734].

van Ham, Maarten; Manley, David 2009: Social housing allocation, choice and neighbourhood ethnic mix in England. In: Journal of Housing \& the Built Environment 24,4: 407-422 [doi: 10.1007/s10901-009-9158-9].

Voas, David 2007: Estimating the Jewish undercount in the 2001 Census: A comment on Graham and Waterman (2005) "Underenumeration of the Jewish population in the UK 2001 Census": Population, Space and Place 11: 89-102. In: Population, Space and Place 13,5: 401-407 [doi: 10.1002/psp.461].

Voas, David; Bruce, Steve 2004: Research note: the 2001 census and Christian identification in Britain. In: Journal of Contemporary Religion 19,1: 23-28 [doi: 10.1080/1353790032000165087]. 
Voas, David; Williamson, Paul 2000: The scale of dissimilarity: Concepts, measurement and an application to socio-economic variation across England and Wales. In: Transactions of the Institute of British Geographers 25,4: 465-481 [doi: 10.1111/j.00202754.2000.00465.x].

Waterman, Stanley; Kosmin, Barry 1987: Ethnic identity, residential concentration and social welfare: the Jews of London. In: Jackson, Peter (Ed.): Race and racism. Hemel Hempstead: Allen \& Unwin: 254-271.

Waters, Mary C.; Jiménez, Tomás R. 2005: Assessing immigrant assimilation: New empirical and theoretical challenges. In: Annual Review of Sociology 31: 105-125 [doi: 10.1146/annurev.soc.29.010202.100026].

White, Michae/ J. 1983: The Measurement of Spatial Segregation. In: American Journal of Sociology 88,5: 1008-1018.

Williams, Bill 1990: "East" and "West": Class and community in Manchester Jewry, 1850-1914. In: Cesarani, David: The Making of Modern Anglo-Jewry. Oxford: Basil Blackwell.

Winkler, Richelle L.; Johnson, Kenneth M. 2016: Moving toward integration? effects of migration on ethnoracial segregation across the rural-urban continuum. In: Demography 53,4: 1027-1049 [doi: 10.1007/s13524-016-0479-5].

Winship, Christopher 1977: A revaluation of indexes of residential segregation. In: Social Forces, 55,4: 1058-1066 [doi: 10.2307/2577572].

Wong, David W. 2016: From aspatial to spatial, from global to local and individual: are we on the right track to spatialize segregation measures? In: Howell, Frank M.; Porter, Jeremy R.; Matthews, Stephen A. (Eds.): Recapturing space: New middle-range theory in spatial demography. Cham: Springer International Publishing: 77-98 [doi: 10.1007/978-3-319-22810-5_5].

Wright, Richard; Ellis, Mark; Parks, Virginia 2005: Re-placing whiteness in spatial assimilation research. In: City \& Community 4,2: 111-135 [doi: 10.1111/j.15406040.2005.00107.x].

Dr. Philip Sapiro ( $₫)$. University of Liverpool, Department of Geography and Planning. Liverpool, United Kingdom. E-mail: psapiro@liv.ac.uk URL: https://www.liverpool.ac.uk/geography-and-planning/research/population-andspatial-analysis/postgraduates/ 


\section{Comparative Population Studies}

WWW.comparativepopulationstudies.de

ISSN: 1869-8980 (Print) - 1869-8999 (Internet)

\section{Published by}

Prof. Dr. Norbert F. Schneider

Federal Institute for Population Research D-65180 Wiesbaden / Germany

\section{(c) BY-SA}

2019

\section{Managing Editor \\ Prof. Philip Rees \\ Dr. Katrin Schiefer}

\section{Copy Editor}

Julia Luther

\section{Editorial Assistant}

Beatriz Feiler-Fuchs

Wiebke Hamann

\section{Layout \\ Beatriz Feiler-Fuchs \\ E-mail:cpos@bib.bund.de}

\section{Scientific Advisory Board}

Karsten Hank (Cologne)

Michaela Kreyenfeld (Berlin)

Marc Luy (Vienna)

Natalie Nitsche (Vienna)

Peter Preisendörfer (Mainz)

Zsolt Spéder (Budapest)

Rainer Wehrhahn (Kiel)

\section{Board of Reviewers}

Martin Abraham (Erlangen)

Laura Bernardi (Lausanne)

Hansjörg Bucher (Bonn)

Claudia Diehl (Konstanz)

Andreas Diekmann (Zurich)

Gabriele Doblhammer-Reiter (Rostock)

Jürgen Dorbritz (Wiesbaden)

Anette Eva Fasang (Berlin)

E.-Jürgen Flöthmann (Bielefeld)

Alexia Fürnkranz-Prskawetz (Vienna)

Beat Fux (Salzburg)

Joshua Goldstein (Berkeley)

Sonja Haug (Regensburg)

Hill Kulu (Liverpool)

Aart C. Liefbroer (The Hague)

Kurt Lüscher (Konstanz)

Emma Lundholm (Umeå)

Nadja Milewski (Rostock)

Dimiter Philipov (Vienna)

Roland Rau (Rostock)

Tomáš Sobotka (Vienna)

Jeroen Spijker (Barcelona)

Olivier Thévenon (Paris)

Helga de Valk (Brussels)

Heike Trappe (Rostock)

Michael Wagner (Cologne) 